\title{
Seismic Waveform Characterization at LLNL: Analyst Guidelines and Issues
}

\author{
F. Ryall, C.A. Schultz
}

November 1, 2001 


\section{DISCLAIMER}

This document was prepared as an account of work sponsored by an agency of the United States Government. Neither the United States Government nor the University of California nor any of their employees, makes any warranty, express or implied, or assumes any legal liability or responsibility for the accuracy, completeness, or usefulness of any information, apparatus, product, or process disclosed, or represents that its use would not infringe privately owned rights. Reference herein to any specific commercial product, process, or service by trade name, trademark, manufacturer, or otherwise, does not necessarily constitute or imply its endorsement, recommendation, or favoring by the United States Government or the University of California. The views and opinions of authors expressed herein do not necessarily state or reflect those of the United States Government or the University of California, and shall not be used for advertising or product endorsement purposes.

This work was performed under the auspices of the U.S. Department of Energy by the University of California, Lawrence Livermore National Laboratory under Contract No. W-7405-Eng-48.

This report has been reproduced directly from the best available copy.

Available electronically at http://www.doe.gov/bridge

Available for a processing fee to U.S. Department of Energy

and its contractors in paper from

U.S. Department of Energy

Office of Scientific and Technical Information

P.O. Box 62

Oak Ridge, TN 37831-0062

Telephone: (865) 576-8401

Facsimile: (865) 576-5728

E-mail: reports@adonis.osti.gov

Available for the sale to the public from

U.S. Department of Commerce

National Technical Information Service

5285 Port Royal Road

Springfield, VA 22161

Telephone: (800) 553-6847

Facsimile: (703) 605-6900

E-mail: orders@ntis.fedworld.gov

Online ordering: http://www.ntis.gov/ordering.htm

OR

Lawrence Livermore National Laboratory

Technical Information Department's Digital Library

http://www.llnl.gov/tid/Library.html 


\title{
Seismic Waveform Characterization at LLNL: Analyst Guidelines And Issues
}

\author{
Flori Ryall* \\ Multimax, Inc. \\ Craig A. Schultz \\ Lawrence Livermore National Laboratory \\ Geophysics and Global Security Division \\ Energy and Environment Directorate \\ 7000 East Avenue \\ Livermore, CA 94551
}

\begin{abstract}
In the first section of this paper we present an overview of general set of procedures that we have followed in seismic waveform analysis. In the second section we discuss a number of issues and complexities that we have encountered in analysis of events in the Middle East, North Africa, Europe, and parts of the European Arctic. To illustrate these complexities we can include examples of waveforms recorded over a variety of paths in these regions.
\end{abstract}

\section{Introduction}

In the Introduction to the excellent textbook Anatomy of Seismograms, the author, O. Kulhanek (1990), quotes E. Wiechert's admonition, “... jede Zacke, jede Zonge zu erklaren...” which translates as "... every jerk, every wiggle should be explained ..." In the process of seismically characterizing different regions we believe Wiechert's suggestion should be followed, provided that the analyst has determined that particular jerks or wiggles can be used in a consistent way to define significant features of recordings for specific source-receiver paths. On the one hand, this requires considerable cross-checking to make sure that the features are repeated from event to event for the path of interest; on the other, it requires that the analyst have sufficient practical experience and basic seismological knowledge to determine that these features are likely to be of interest to the regional calibration research program. A "senior analyst" must be proficient with all analysis tools, thoroughly understand processed data parameters, be able to differentiate a variety of noise types from true seismic detections, be proficient with data from all distance ranges, be able to resolve mixed or otherwise complex events without help, and have sufficient knowledge to recognize problems with the instruments and/or event locations received from the agencies supplying the data.

In our approach to regional calibration, while consistency is essential to insure that the analysis results have high credibility, the actual procedures followed vary from event to event depending on event size, path complexity and other characteristics. Thus, large, well-recorded teleseismic events might be analyzed in a straightforward way with minimal processing of the data if the main objective is to list parameters only for prominent phases. However, analysis of even large events can involve considerable processing if the analysis includes all recorded phases, or if the analyst is searching for anomalous arrivals that will help researchers identify a particular path or event type. This situation is even more complicated in the case of small regional events for which

\footnotetext{
* Seismic analyst residing at Lawrence Livermore National Laboratory under contract from Multimax.
} 
the signals themselves are complex and tend to be buried in noise, and/or when the paths cross varying types of geophysical structure.

It should be noted that the single most important tool used in our analysis, for large as well as small events, is bandpass filtering of the signals to enhance particular arrivals, separate mixed phases or detect small but important arrivals buried in noise. Removal of instrument response in such a process would not improve the results, and is therefore not part of the initial data processing; however, instrument calibration is taken into account in determining amplitudes, waveform modeling and other procedures that are handled by the various seismologist groups as post-analysis tasks.

While it would be at best difficult (and maybe impossible) to list a detailed set of analysis requirements for regional seismic characterization research, it is possible to give examples of various issues that have arisen during our analysis of seismic paths that traverse the numerous tectonic regions about the globe. The following section focuses on a number of such examples, and these are intended to highlight for the seismic analyst the sorts of issues that can arise in attempting to characterize a region. These are not all-inclusive, since the addition of new seismic stations or the occurrence of events in a new source area within a region under study will lead to new source-receiver paths, and each of these will have a unique set of signal features and potential analysis problems. A catalog of standard phase measurements plus observations like those given below, together with knowledge of tectonic and geologic features of the region, comprise the building blocks that can then be used by seismologists to determine regional structure, model observed variations in seismic signatures, identify structural features that lead to anomalous phases, and improve event location and amplitude analysis.

In the following section we present some general analysis guidelines used at LLNL for phase quality designations, naming of anomalous phases, assumed crossover distances, etc., in characterizing the regions listed above. In characterization analysis for other regions, this list might have to be somewhat modified or expanded. 


\section{General Analysis Guidelines Followed at LLNL}

Although, for the reasons stated above, analysis procedures must be flexible enough to provide the experienced analyst sufficient latitude to handle the many complexities that arise in regional characterization, there are a few general guidelines that we have followed whenever possible. These are listed below.

- For consistency, all the high quality picks for location should be made by as few analysts as possible.

- At a minimum phase quality designations (A, B, C, D, F) are assigned to Pn, P, Sn, S and Lg. Quality designations should be related to arrival time error bounds. If the analyst has the flexibility to specify an adjustable error bar directly on the seismogram, then that is preferred.

- Lg is identified for all events, even for long continental paths where blockages are not expected.

- Stations determined to have clock errors above a certain critical value have first $P$ arrivals identified with "CE" instead of a phase name. It should be noted that clock errors of on the order of a few seconds are difficult to confirm. The occurrence of unusual outliers in traveltime for similar paths to a given station might indicate timing problems.

- By default the crossover distance for $\mathrm{Pn} / \mathrm{P}$ and $\mathrm{Sn} / \mathrm{S}$ is taken as a fixed value. Exceptions to this rule are made whenever low-frequency content indicates that the phases under consideration are probably $\mathrm{P}$ or $\mathrm{S}$ rather than $\mathrm{Pn}$ or $\mathrm{Sn}$, respectively. At certain distances both regional and teleseismic arrivals are sometimes observed and reported.

- For events with sub-crustal depth, the phase names "P" and " $S$ " are used for all distance ranges.

- Many mid-band or long-period surface-wave onsets are difficult to time accurately, for a variety of reasons. As a result, arrival times for such phases should be viewed as an indication that the phase was observed, and should not be used in studies aimed at constructing traveltime curves.

- Generic phase names are used for phases that are real but do not fit standard traveltime branches. Real is defined as a phase that is significant and is found to be consistent for other similar paths.

- A higher-mode Rayleigh wave propagating with about the same velocity as $S$ is labeled as a separate phase. This phase is added only when clearly recorded.

- If there is ambiguity in naming a phase, a seismologist is consulted. Until a decision is made the phase is labeled with a generic phase name.

- A broad range of filter bands are explored to enhance the signal to noise for each phase. Filter bands are stored in the database for later researcher and analyst review.

- If travel-times have large delays while other similar paths do not, then the station is assumed to have a clock error.

- P waves and Rayleigh waves are picked on the vertical component. In the rare case that the vertical component does not exist, we pick on the horizontal components. S wave and Love waves are picked on the horizontal components. 
- When filtering an event in a region, past events from the same source region are checked to expedite and provide consistency for picks in the region.

- "Remarks" are added to indicate instrument or signal problems, and to describe anomalous phases.

- The guidelines above are common to all regions. We further allow the analyst to define additional region dependent guidelines as the data requires. This is always documented.

Note on waveform analysis process specific to seismic amplitude analysis

As noted above, all the arrival time picks made at LLNL and used in location calibration are made by a single analyst at LLNL, Flori Ryall. Seismic waveform analysis is also done by others at LLNL, primarily for amplitude analysis purposes, and particularly when Flori's picks are not available for specific waveforms. We are able to easily sort out these different arrivals by using their author information in the database arrival table.

The goals of the amplitude analysis purposes are slightly different than those in location. For location accurate timing of phase onsets is critical, whereas for amplitude measurements other issues can be more important since small time shifts in the measurement window only have a small effect on RMS or frequency domain amplitudes. On the other hand the behavior of the particular phases, their blockage and determining the correct measurement window for amplitude and source-distance processing are paramount. For this reason the arrivals do not include an estimated onset uncertainty except to flag gross timing errors. For amplitude analysis we use the time picks to define beginning and ending group velocity windows appropriate for each regional phase for a particular station and event source region for future automated processing. We make use of small time shifting to account for small mislocation and/or origin time errors. We also take care to flag events with quality or other problems (e.g. multiple event contamination, glitch, mislabeled deep event, etc.) that should not be processed or need to be processed as a separate group. In going through our waveform amplitude analysis we use most of the same principles outlined here in terms of making use of multiple bandpass filters and noting regional variation in the behavior of seismic phases. A fuller description of the waveform analysis procedures specific to amplitude processing will be the subject of a future document. 


\section{Analysis Issues}

The following set of figures provide examples of various issues that were encountered during our analysis of seismic paths that traverse various tectonic regions. This section focuses on a number of specific examples that are intended to highlight for the seismic analyst and researcher the sorts of issues that can arise in attempting to characterize a region. These are not all-inclusive since each new station and region may have a unique set of specific signal features and other potential analysis problems.

\section{List of Issues:}

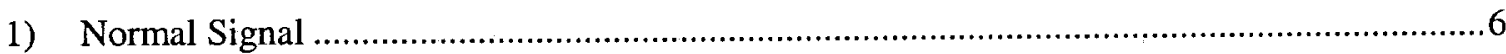

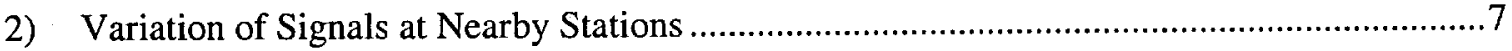

3) Use of Narrow-Band Filters to Identify Various Phases ................................................... 8

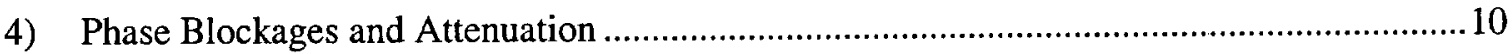

5) Phase Arrival Times Different than Predicted .................................................................14

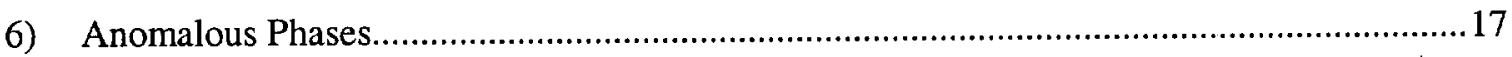

7) Effects of Magnitude Variation on Arrival Time Picks .....................................................2

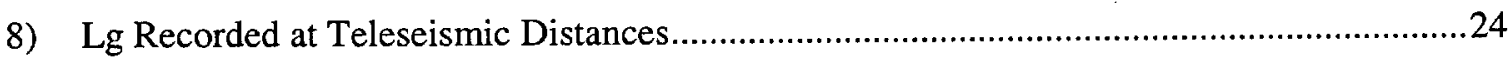

9) Possible Complexity at Crossover and Triplication Distances...........................................25

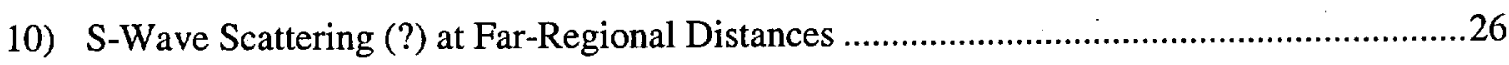

11) Mixed Events,Interference Due to Local Earthquakes and Noise ......................................2

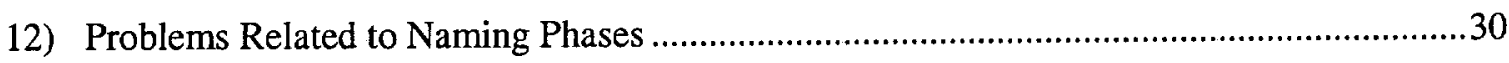

13) Quality Control and Documentation of Unusual Observations ..........................................31

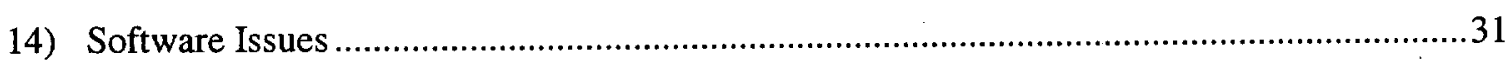

In the figures that follow, the labels to the left of the trace have the station designator and channel (top line), the distance in degrees (middle line), and the filter band in $\mathrm{Hz}$ (bottom line). Examples are presented to illustrate different analysis issues, indicated by the numbered section headings (in italics). 
1) Normal Signal: Figure 1

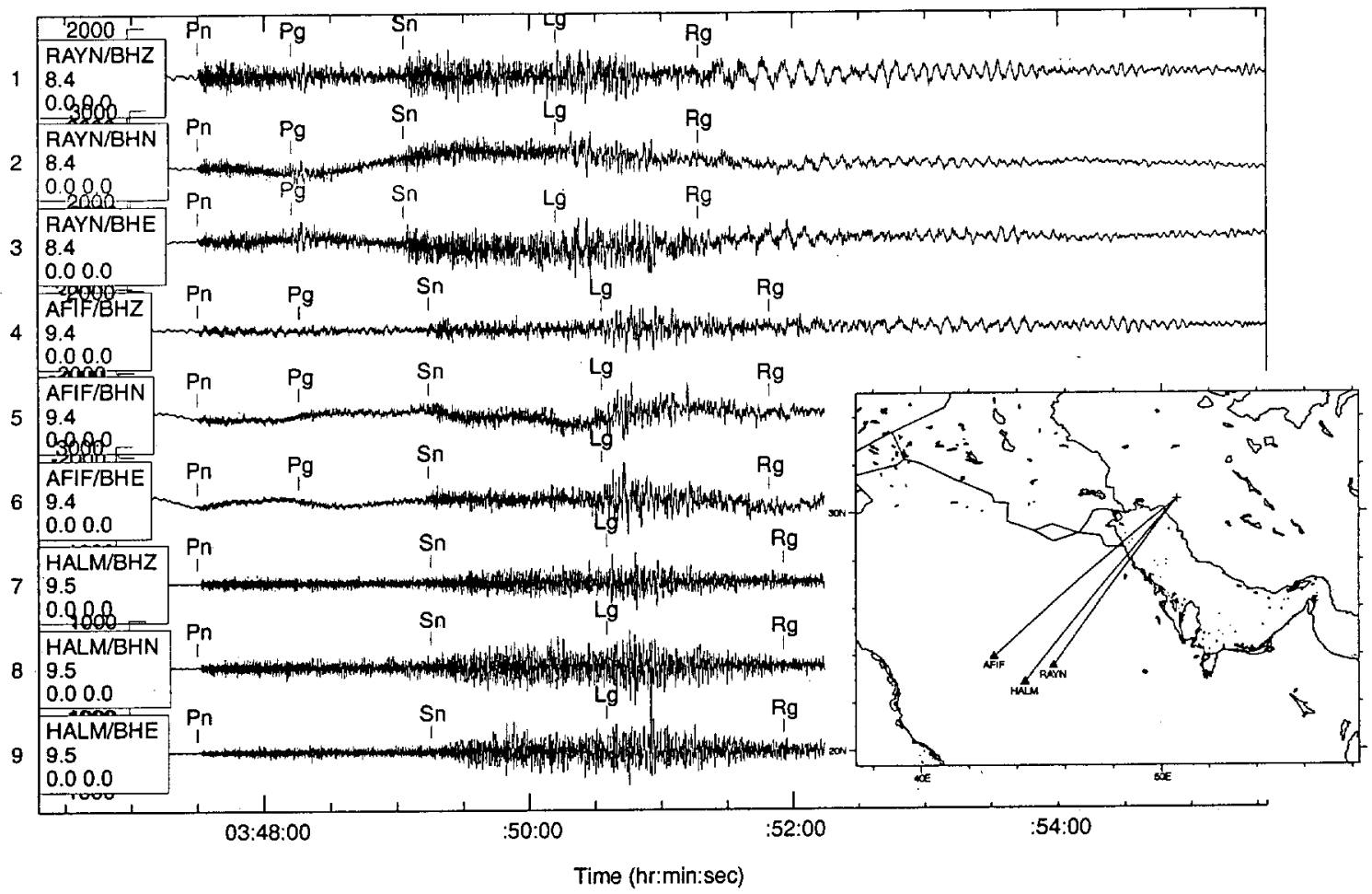

Figure 1. Zagros Mts, Iran $\mathrm{h}=33 \mathrm{Km} \mathrm{mb} 4.6$

Figure 1 shows recordings at three Saudi Arabian stations for an event in the western Zagros Mountains. Source-receiver distances for the stations are $8.4^{\circ}-9.5^{\circ}$. Arrivals picked on the recordings include the standard regional phases $\mathrm{Pn}, \mathrm{Pg}, \mathrm{Sn}, \mathrm{Lg}$ and $\mathrm{Rg}$. Although some of the onsets, such as Pg and $\mathrm{Sn}$, are not obvious on all the stations, as will be explained below filtering is used extensively for signal enhancement in our analysis. For station HALM, the Pg phase could not be seen even with filtering. 
2) Variation of Signals at Nearby Stations: Figure 2

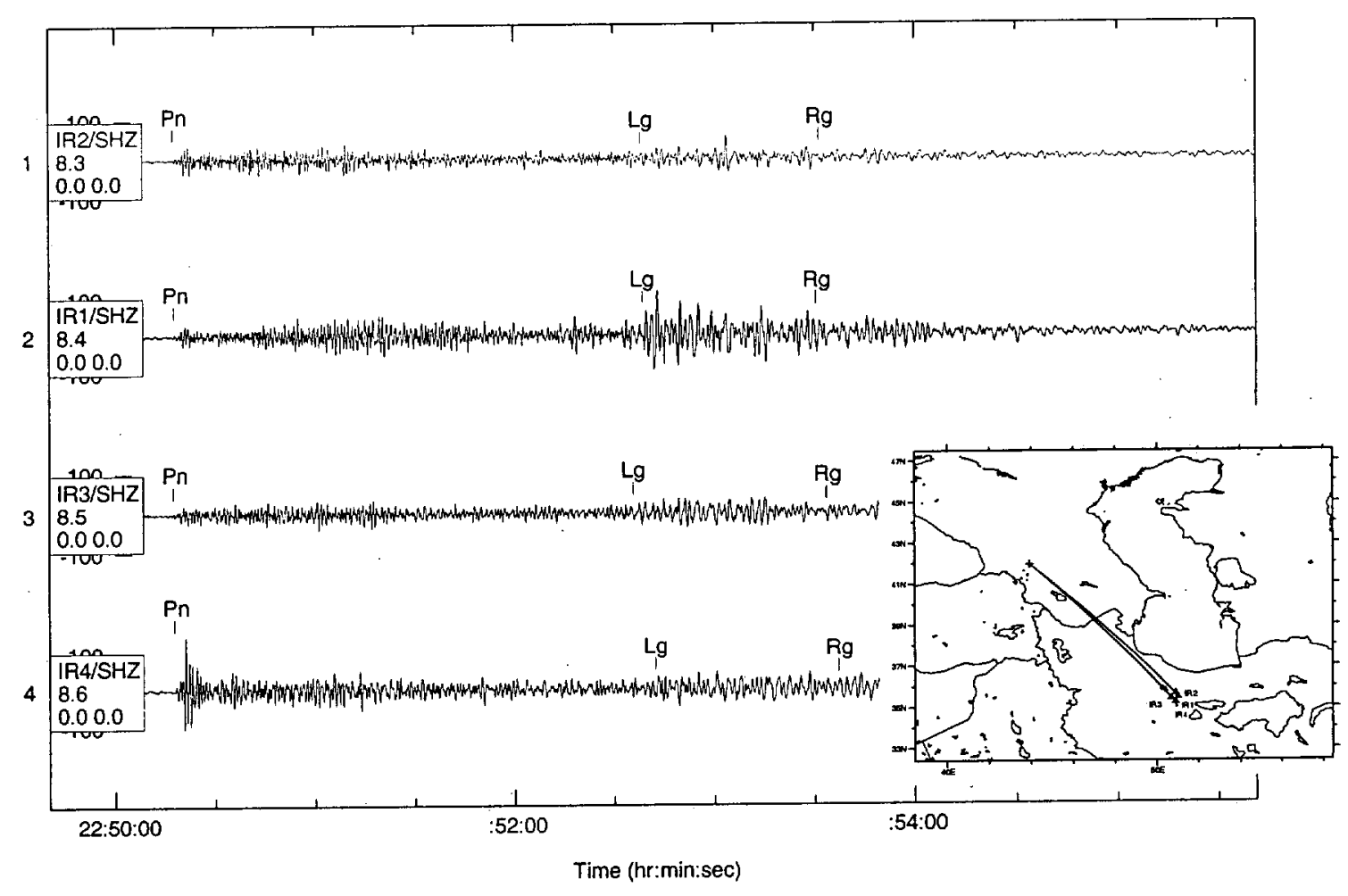

Figure 2. Caucasus Mountains, Russia $\mathrm{h}=10 \mathrm{Km} \mathrm{mb} 4.8$

Figure 2 shows an event in Georgia, Former Soviet Union (FSU), recorded at four elements of the ILPA array in Iran, distances $8.3^{\circ}-8.7^{\circ}$. These unfiltered traces show the variation in amplitude that can occur for a single event, even at stations that are separated from each other by less than $50 \mathrm{~km}$. Since the traces are all to the same scale, it can be seen that amplitude variations affect both $\mathrm{Pn}$ and $\mathrm{Lg}$; the $\mathrm{Lg} / \mathrm{Pn}$ ratio varies by about a factor of 8 . 
3) Use of Narrow-Band Filters to Identify Various Phase: Figures $3 a, 3 b, 4$

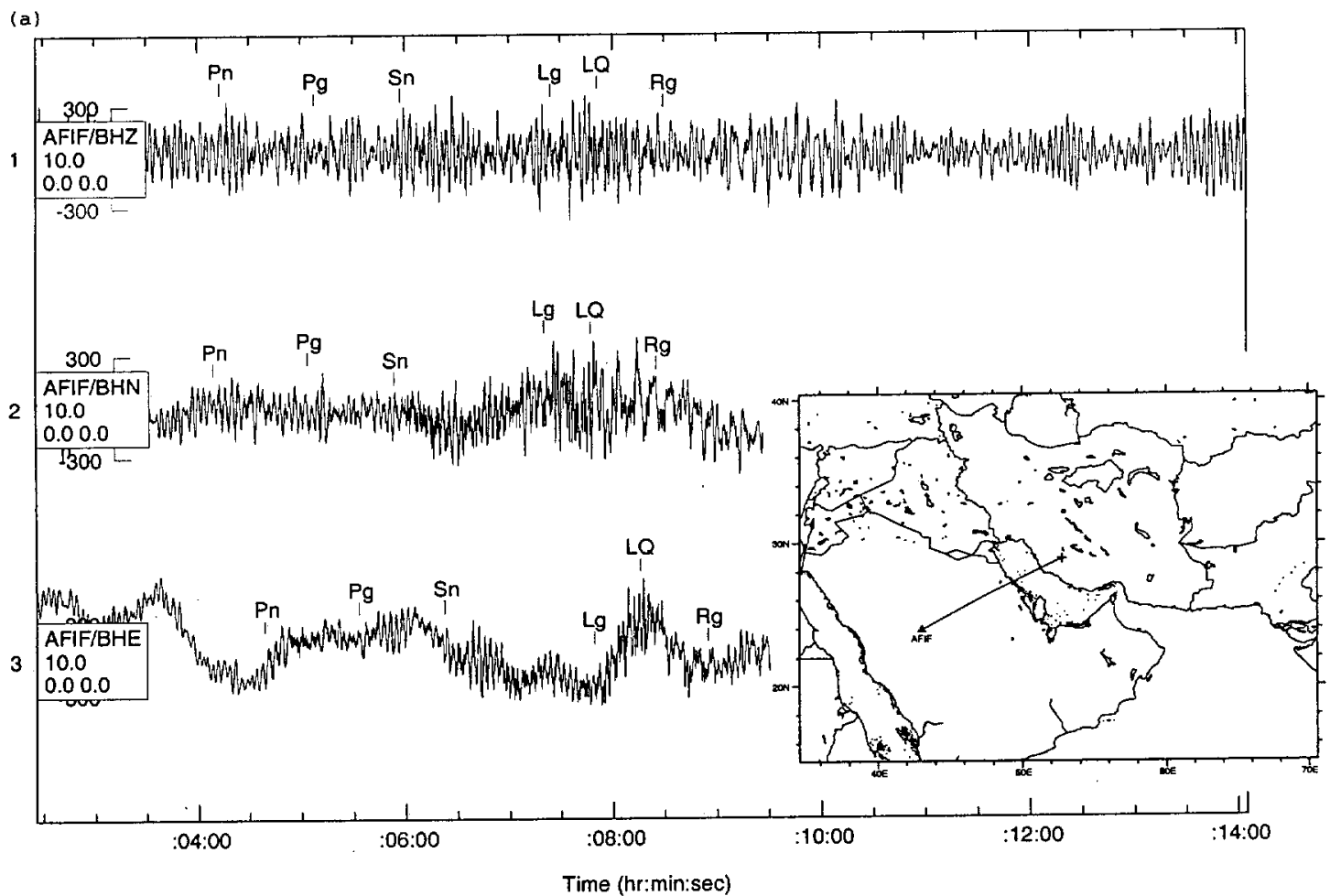

(b)

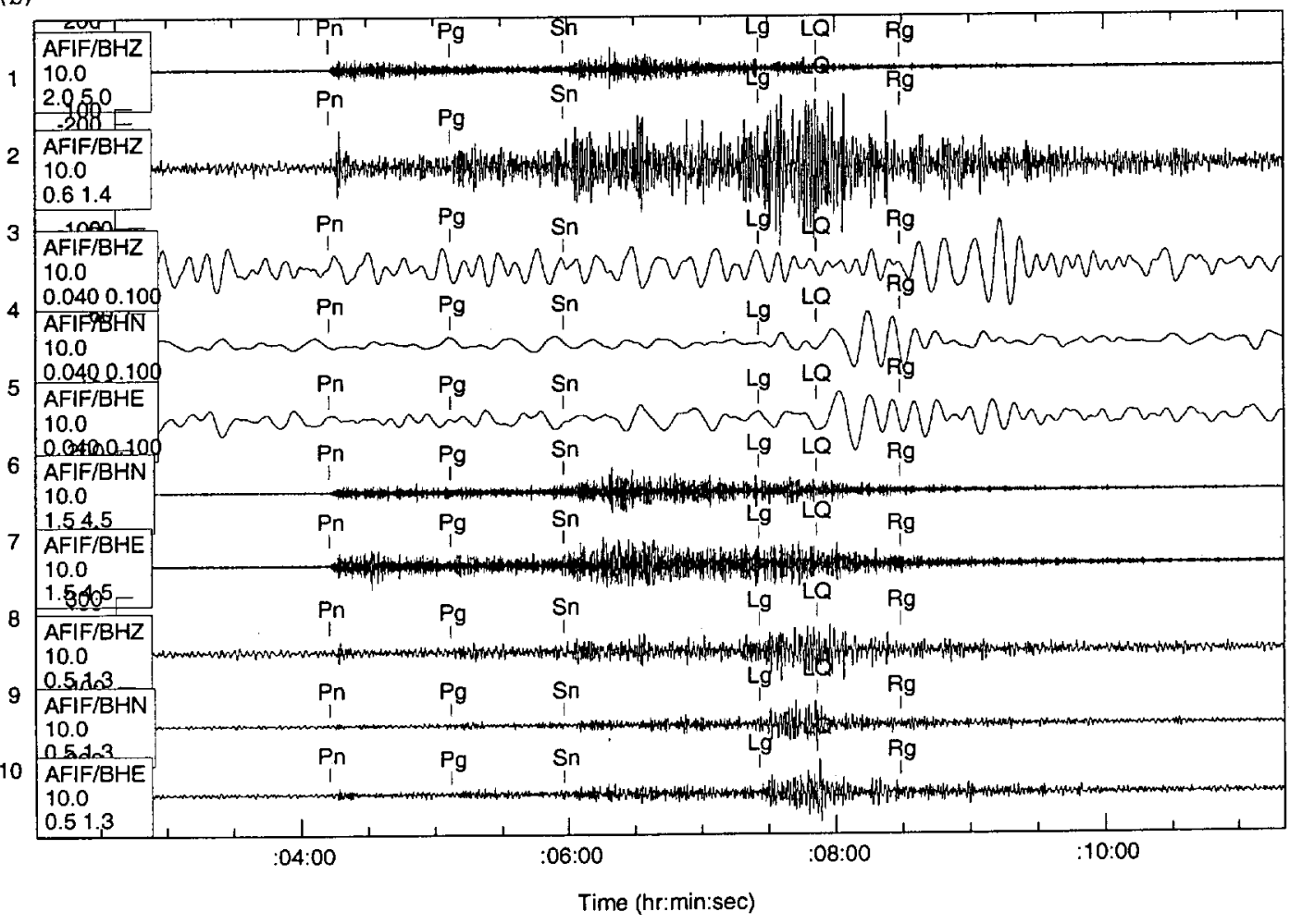

Figure 3. (a) Zagros Mts, Iran $\mathrm{h}=33 \mathrm{Km} \mathrm{mb} \mathrm{4.2,} \mathrm{(b)} \mathrm{Zagros} \mathrm{Mts,} \mathrm{Iran} \mathrm{h=33} \mathrm{Km} \mathrm{mb} \mathrm{4.2.}$ 


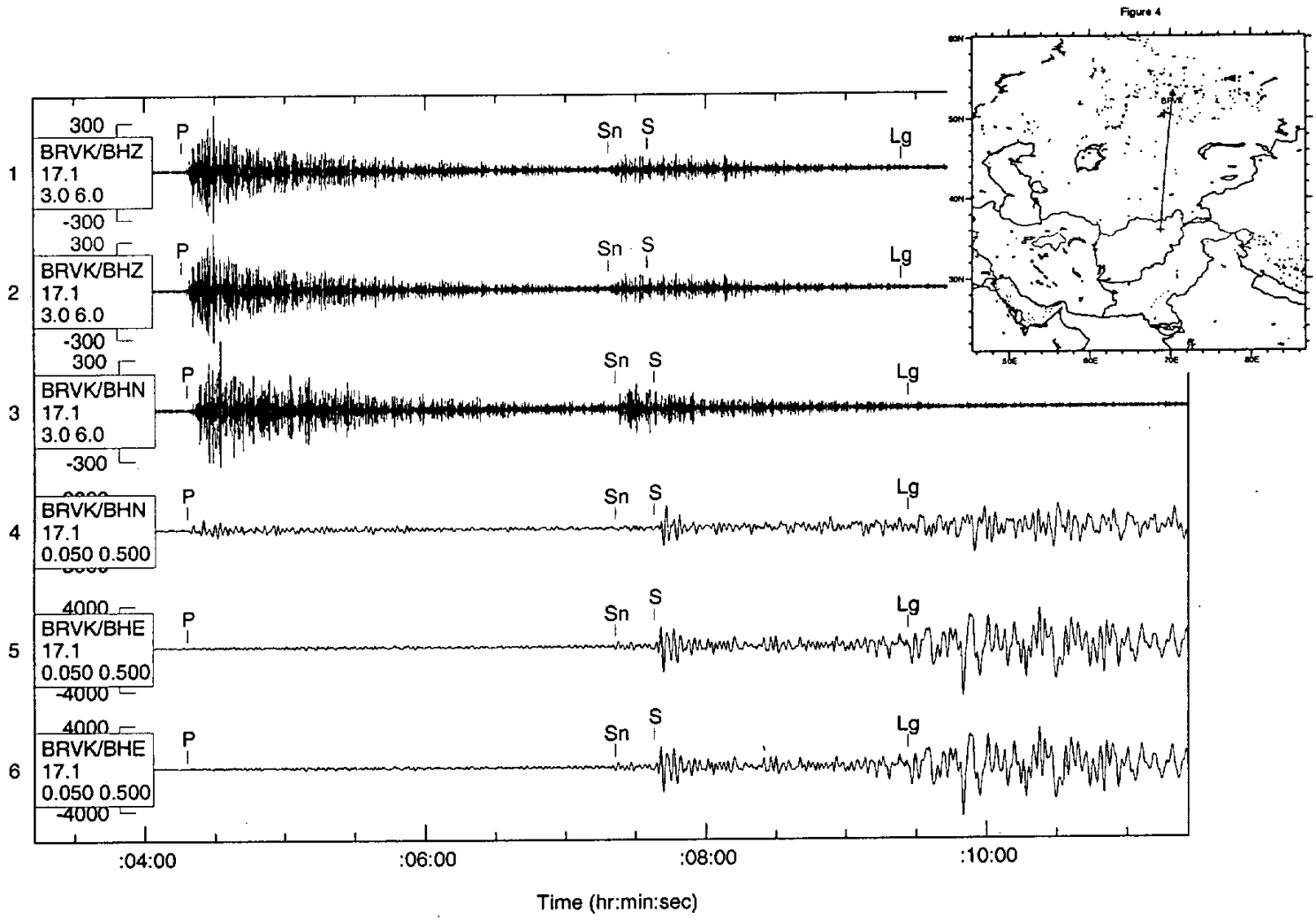

Figure 4. Afghanistan $\mathrm{h}=33 \mathrm{Km}$ mb 5.1

Figure 3a shows an event in the Zagros Mountains, Iran, recorded at Saudi station AFIF, distance of $10.0^{\circ}$. This is a moderate-sized event, $\mathrm{mb} 4.2$, yet on the unfiltered broadband traces of Figure $3 \mathrm{a}$ the seismic signal is almost totally obscured by noise. For the same station, Figure $3 \mathrm{~b}$ shows how the various phases for this event were enhanced by narrow-band filtering: $2.0-5.0 \mathrm{~Hz}$ for Pn (top trace), $0.6-1.4 \mathrm{~Hz}$ for $\mathrm{Pg}$ (next trace), $0.04-0.1 \mathrm{~Hz}$ for Rg and LQ (next three traces), 1.5-4.5 $\mathrm{Hz}$ on the horizontal traces for $\mathrm{Sn}$ (next two traces), and $0.5-1.3 \mathrm{~Hz}$ for $\mathrm{Lg}$ (bottom three traces). While the same filter settings may not work for other events at other distances recorded by other stations, this example shows that none of the picks for this event could have been made with any degree of confidence without filtering.

Another example is shown on Figure 4, an Afghan event recorded at station BRVK in Kazakhstan, distance of $17.1^{\circ}$. In this case the phases $P$ and $S n$ can be seen on traces filtered in the band 3.0-6.0 Hz. However, a teleseismic S-wave can be seen in a different passband, 0.05-0.5 $\mathrm{Hz}$. Such arrivals are important in defining crossover distances for regional and teleseismic phases in a regional characterization program. 


\section{4) Phase Blockages and Attenuation: Figures 5, 6a, $6 b$}

A significant part of the LLNL research program has been directed at identifying areas where particular regional phases are blocked or attenuated.

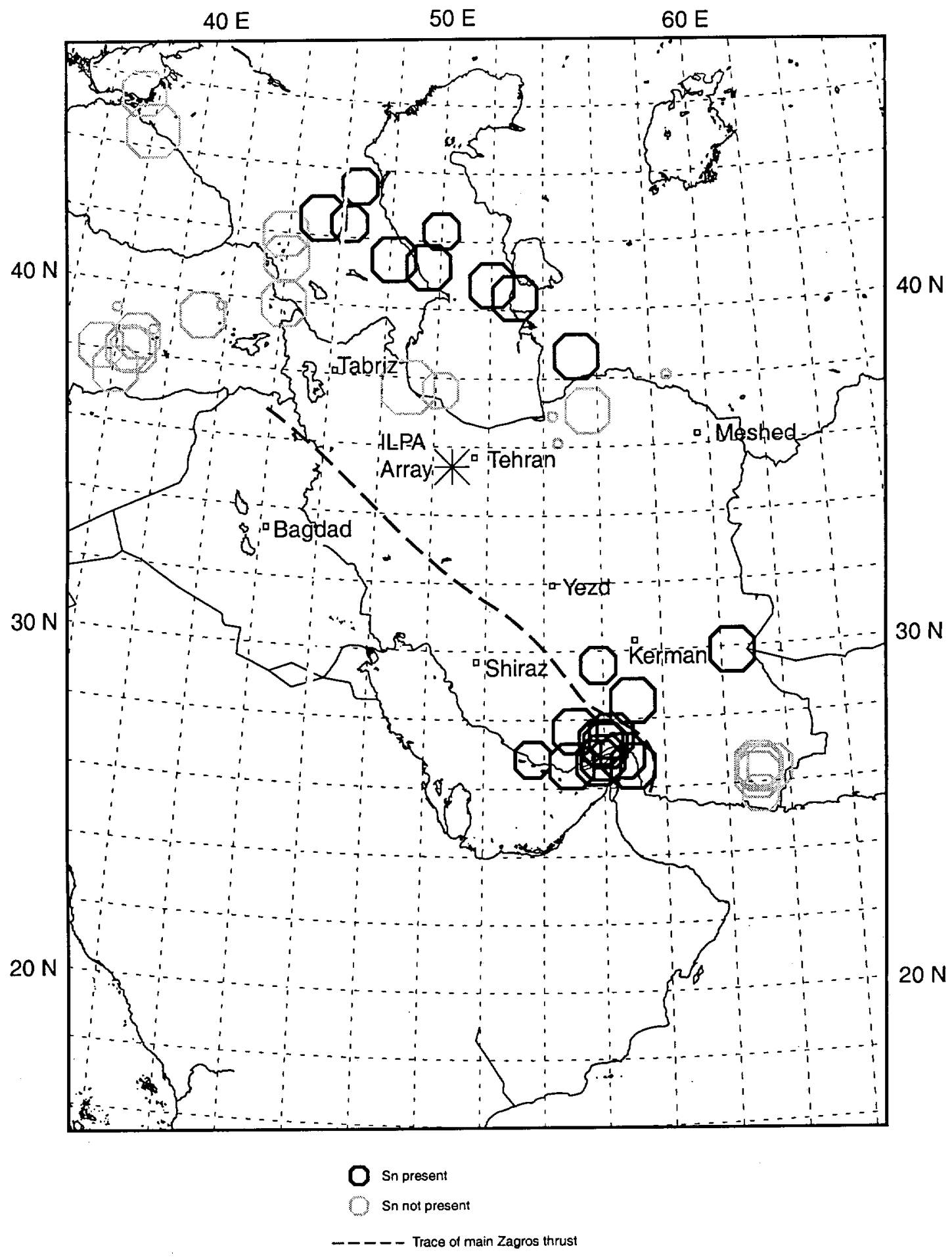

Figure 5: Map of Sn propagation and blockage in the Iranian region for ILPA array. 
As shown by Figure 5, in an area southeast of Shiraz the ILPA array records Sn, while for an adjacent area to the east (Makran Range) the opposite is true (Sweeney, 1996). 
(a)

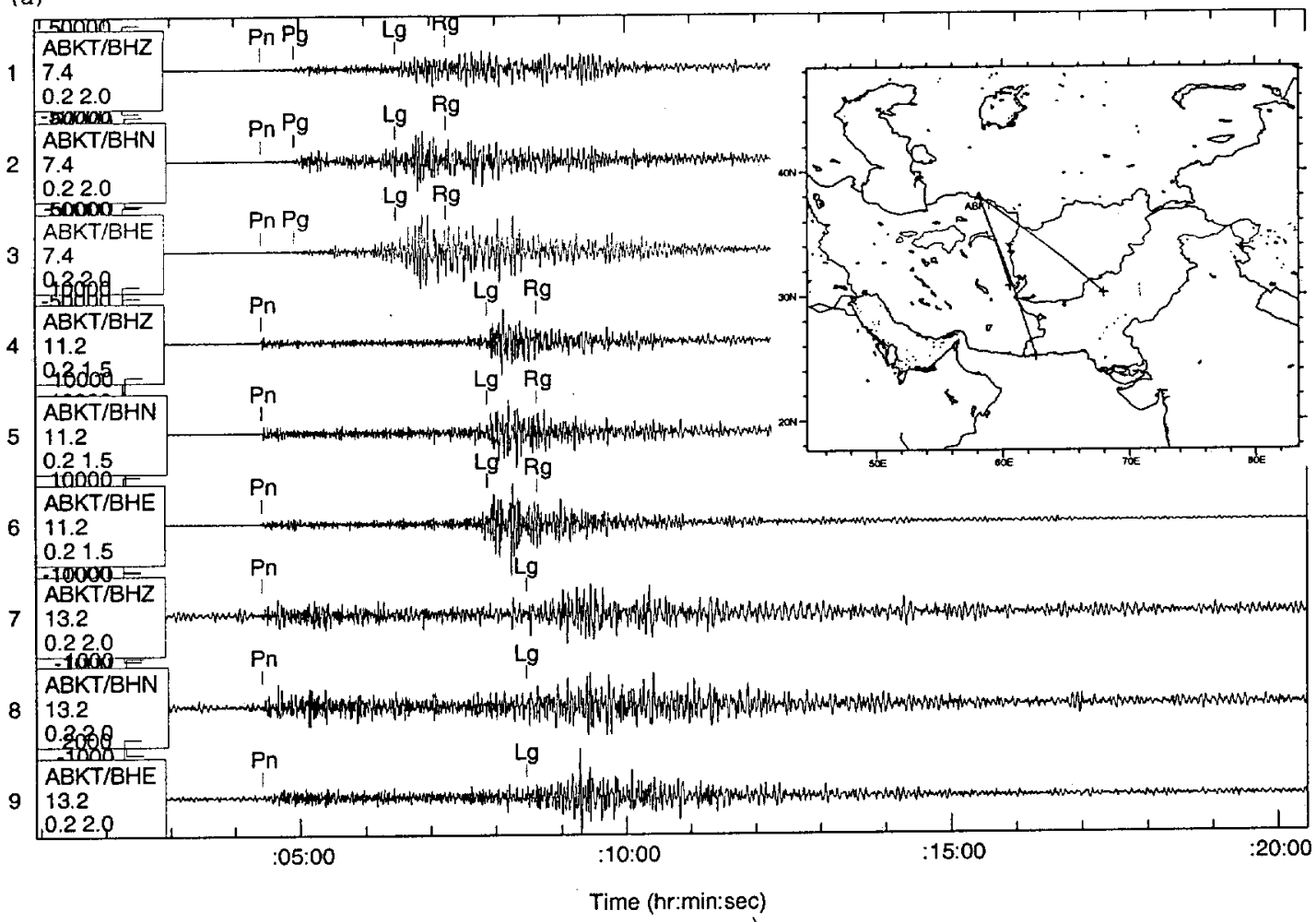

(b)

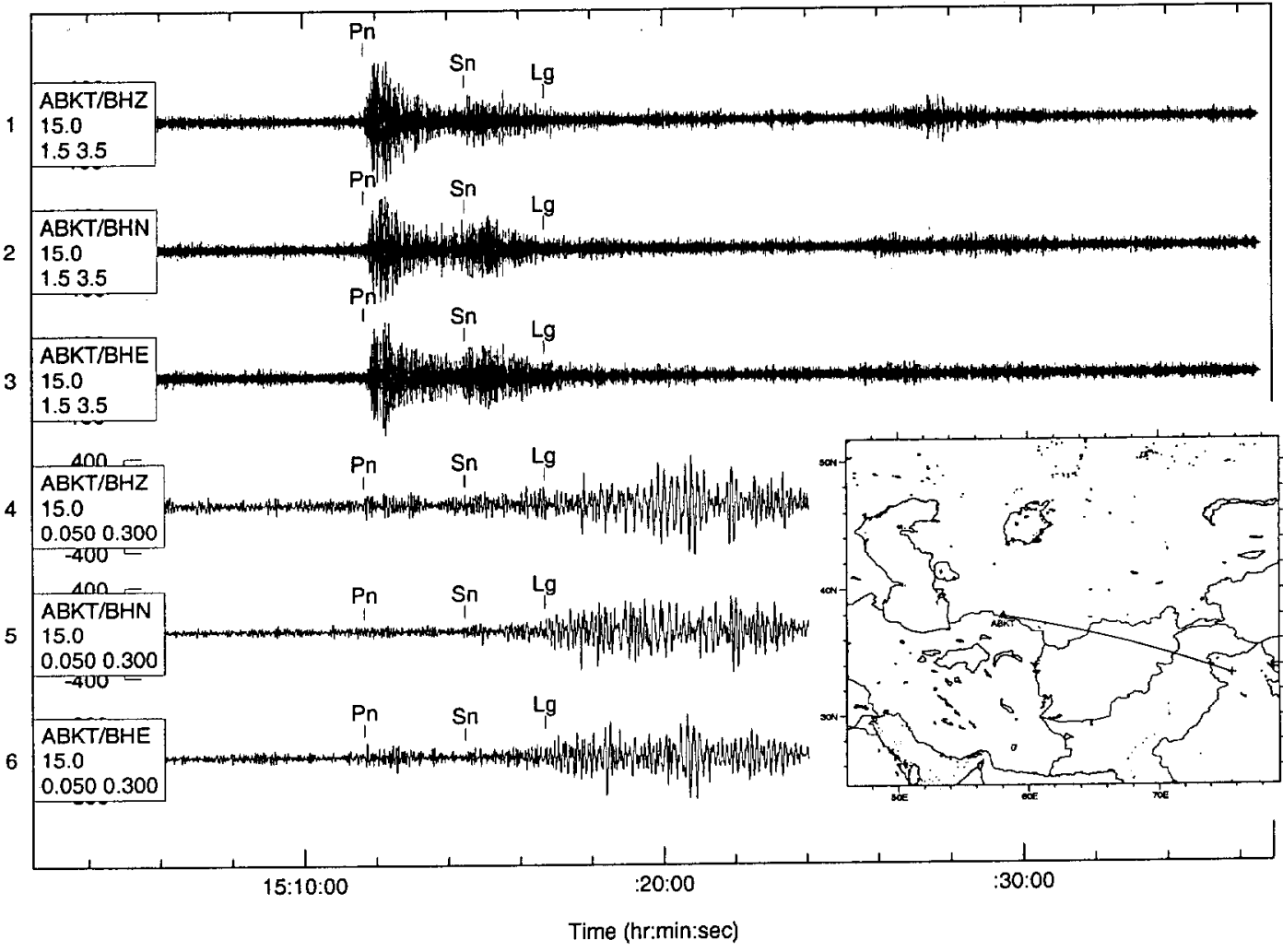


Figure 6. (a) Traces 1-3 Eastern Iran, Traces 4-6 N. Central Pakistan, Traces 7-9 Western Pakistan, (b) Northern India, h=33 Km mb 5.0.

Figures $6 \mathrm{a}$ and $6 \mathrm{~b}$ illustrate a similar situation for the station ABKT in Turkmenistan. Three events Pakistan and Iran at distances of $7.4^{\circ}-13.2^{\circ}$ record Pn and $\mathrm{Lg}$ phases (Figure 6a), while an event at distance $15.0^{\circ}$ to the ESE in northern India records $\mathrm{Sn}$ as well as Pn and Lg (Figure 6b). Note also that $\mathrm{Lg}$ for the Indian event is lower frequency than for the Pakistan event at a similar distance $\left(13.2^{\circ}\right)$, requiring that different filters be used in picking these recordings $(0.05-0.3 \mathrm{~Hz}$ and $0.2-2.0 \mathrm{~Hz}$, respectively). 
5) Phase Arrival Times Different than Predicted: Figures 7, 8a, 8b, 9

In regions of complex tectonic structure the velocities of regional seismic phases can vary considerably, leading to arrival times that are earlier or later than those predicted by "standard" traveltime curves.

\section{Lg and Sn Velocities (Eastern Mediterranean)}

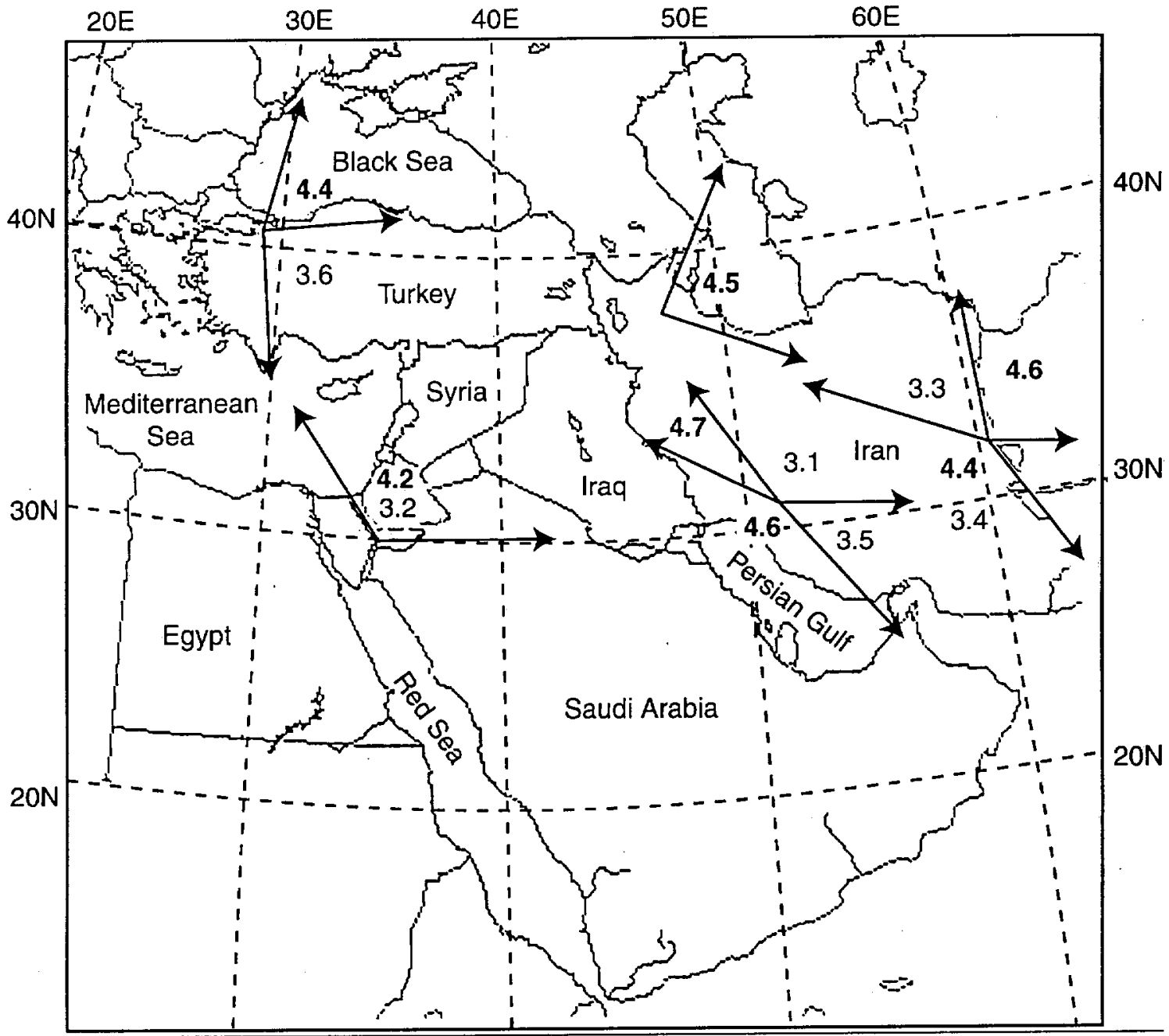

Figure 7. Map of $\mathrm{Lg}$ (regular style) and $\mathrm{Sn}$ (bold style) velocities $(\mathrm{km} / \mathrm{s})$ in the eastern Mediterranean region. Data is after Kadinsky-Cade et al. (1981). Arrows bracket direction of arrival of signals used to determine velocities (each velocity number is bound by two arrows showing the azimuthal limits of signal arrivals used in the determination.)

Figure 7, from a 1981 study by Kadinsky-Cade and others, shows Lg velocities in the Middle East varying from 3.1 to $3.6 \mathrm{~km} / \mathrm{sec}$, while $S n$ velocities vary from 4.2 to $4.6 \mathrm{~km} / \mathrm{sec}$. If the analysis program uses "standard" (e.g., IASPEI) traveltime tables to show expected arrival times of regional phases, actual arrival times can vary significantly from these predictions - up to a minute or more at large regional distance ranges. 

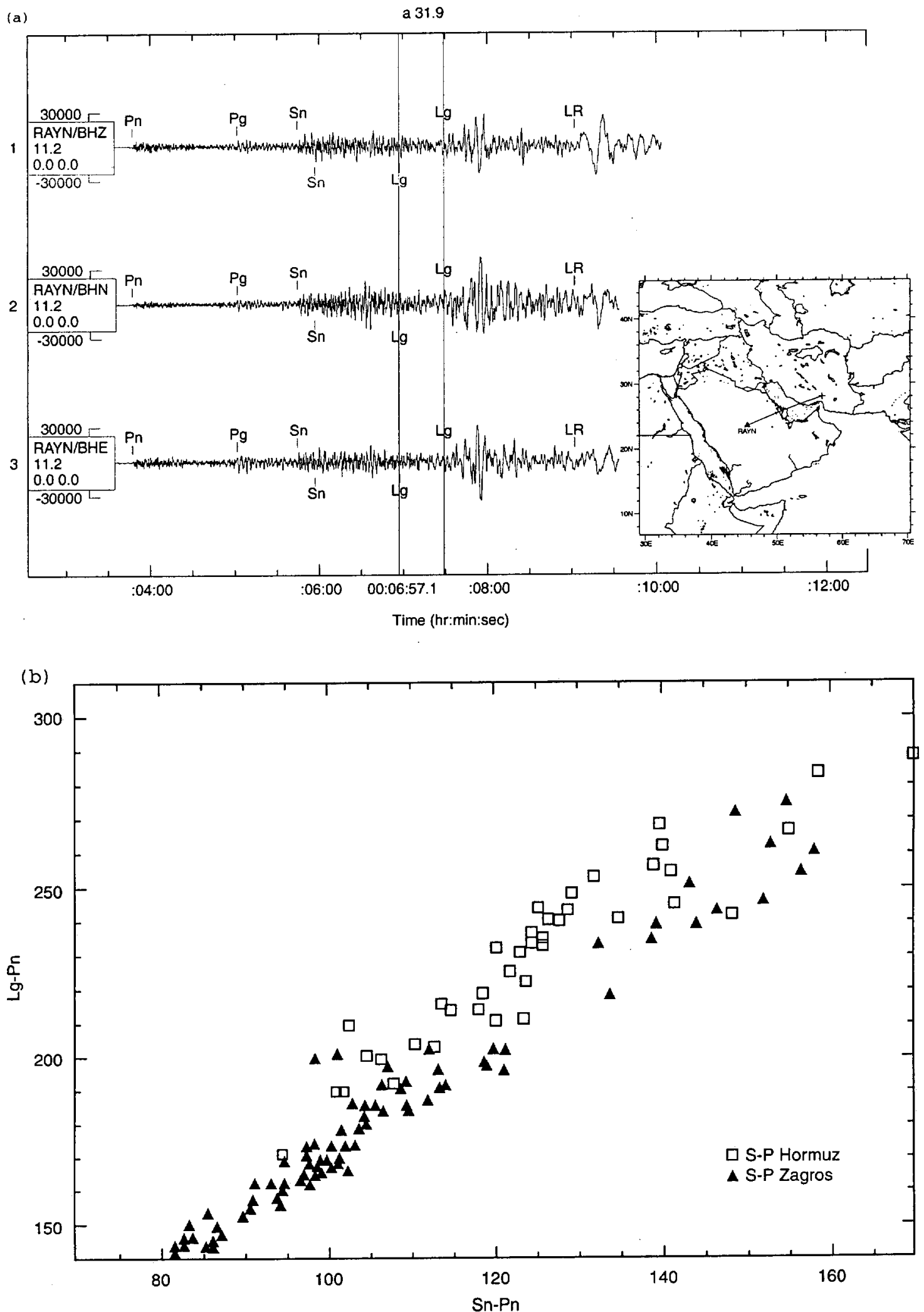

Figure 8. (a) Southwestern Iran $\mathrm{h}=27 \mathrm{Km} \mathrm{mb} 5.5$, (b) Lg-Pn time as a function of Sn-Pn time for the Strait of Hormuz and Zagros event clusters as recorded at the Saudi Net. 
This anomalous behavior is illustrated by Figure 8a, which shows a Hormuz event recorded at Saudi station RAYN. In this case $\mathrm{Lg}$ is later than the predicted time by 32 seconds. In this and other figures, the predicted times are indicated below the trace, analyst picks are above the trace. Observed $\mathrm{Sn}$ is about 10 seconds early. $\mathrm{Pg}$ is also late, although the predicted time is not marked on the record. Figure $8 \mathrm{~b}$ shows that this $\mathrm{Lg}$ behavior is characteristic for the Hormuz region.

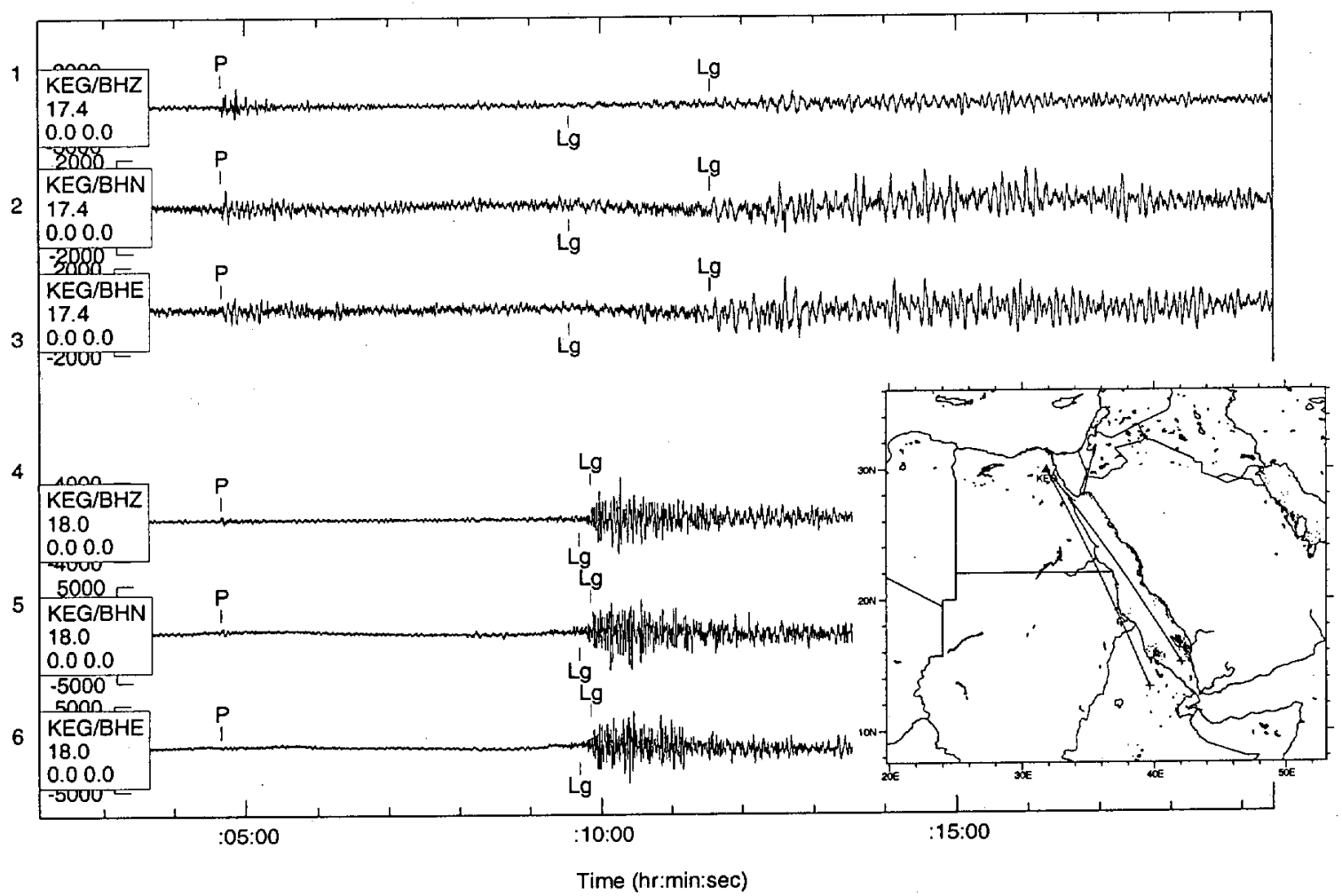

Figure 9. Traces 1-3 Red Sea, $h=10 \mathrm{Km} \mathrm{mb} \mathrm{5.0;} \mathrm{Traces} \mathrm{4-6} \mathrm{Ethiopia,} h=11 \mathrm{Km} \mathrm{mb} 4.9$.

Figure 9 shows an extreme example of similar behavior: For an event at distance $17.4^{\circ}$ from station KEG in Egypt, where the source-receiver path runs through the Red Sea, Lg is about 120 seconds later than the predicted time, while for a nearby event at distance $18.0^{\circ}$ where the path is outside the boundaries of the Red Sea, Lg is only ten seconds late. Note also the substantial difference in apparent frequency content of these two signals. 
6) Anomalous Phase: Figures 10a, 10b, 10c, 11, 12, 13, 14

The identification of anomalous phases is important in regional characterization, as these may be used later to identify particular source-receiver paths and/or help in studying structure along the paths. Several examples are shown in the following figures.

(a)

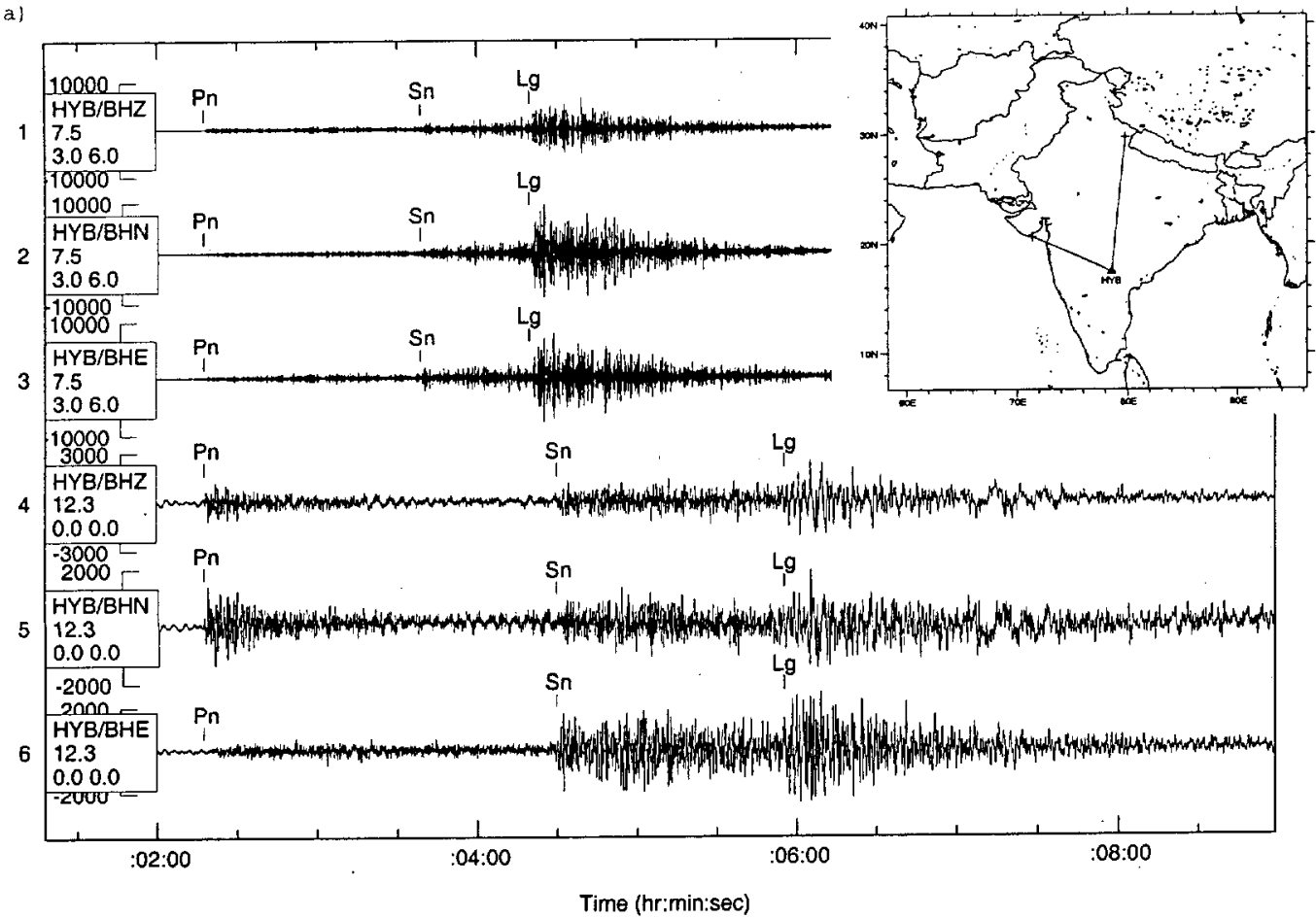

(b)

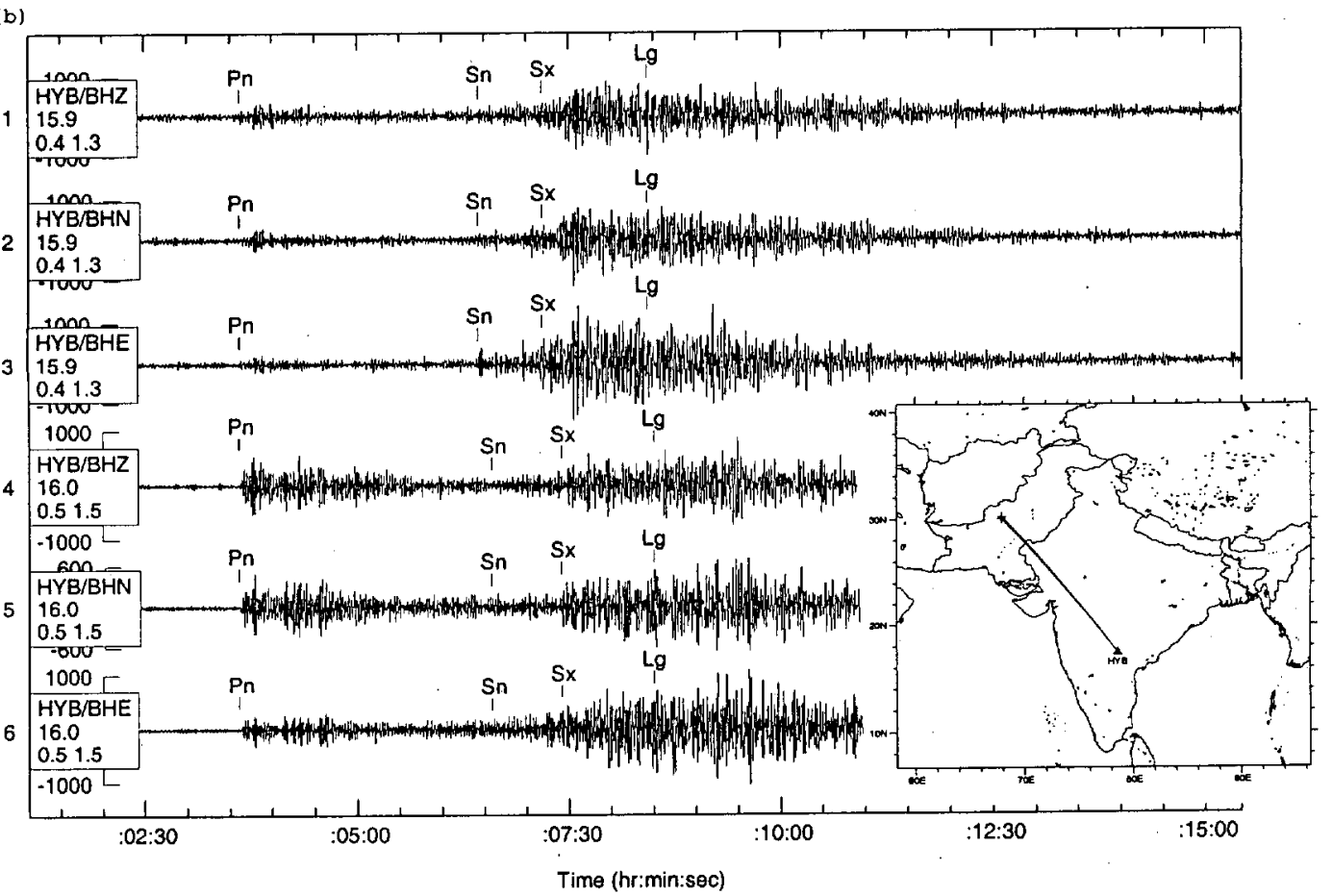




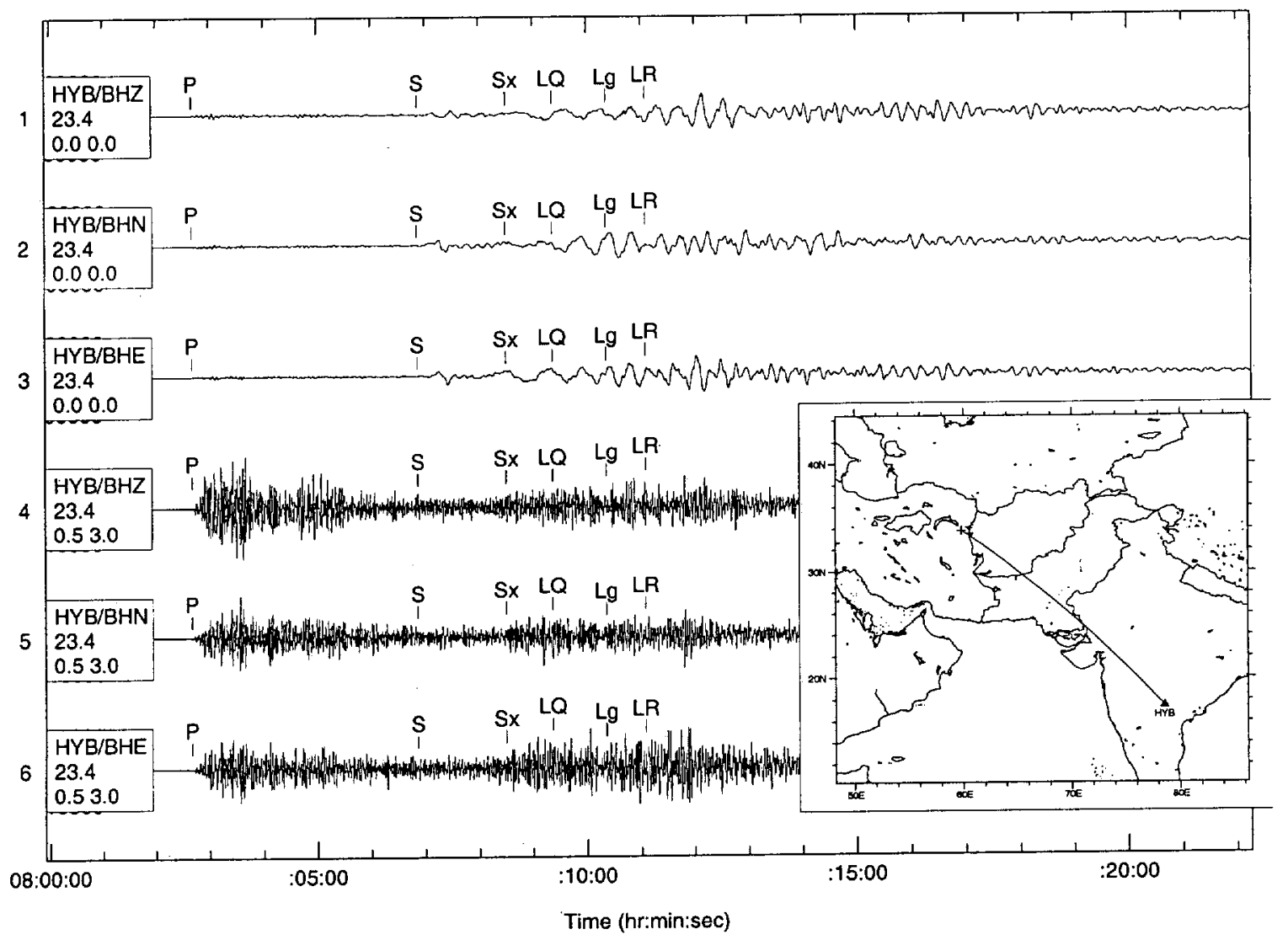

Figure 10. (a) Traces 1-3 Off Northwestern Coast of India, h=25 Km mb 5.0; Traces 4-6 Northeastern India, h=33 Km mb 5.1, (b) N. Central Pakistan, h=25 Km mb 5.0; h=24 Km mb 5.2, (c) N.E. Iran $\mathrm{h}=10 \mathrm{Km} \mathrm{mb} 6.4$.

In Figure 10a, station HYB is seen to record normal Pn, Sn and Lg phases for two events at distances $7.5^{\circ}$ and $12.3^{\circ}$ in northern and western India. However, two events in Pakistan at distances $15.9^{\circ}$ and $16.0^{\circ}$ and in the same azimuth from station HYB have a large, long-duration phase that follows Sn and precedes Lg (Figure 10b). This has been labeled Sx for both events; although the event in the top of the figure has an indeterminate onset. Figure 10c shows that an event in Iran, at approximately the same azimuth but at teleseismic distance of $23.4^{\circ}$ from HYB, has a short-period Sx phase in addition to $\mathrm{Lg}$ and a number of teleseismic phases. 


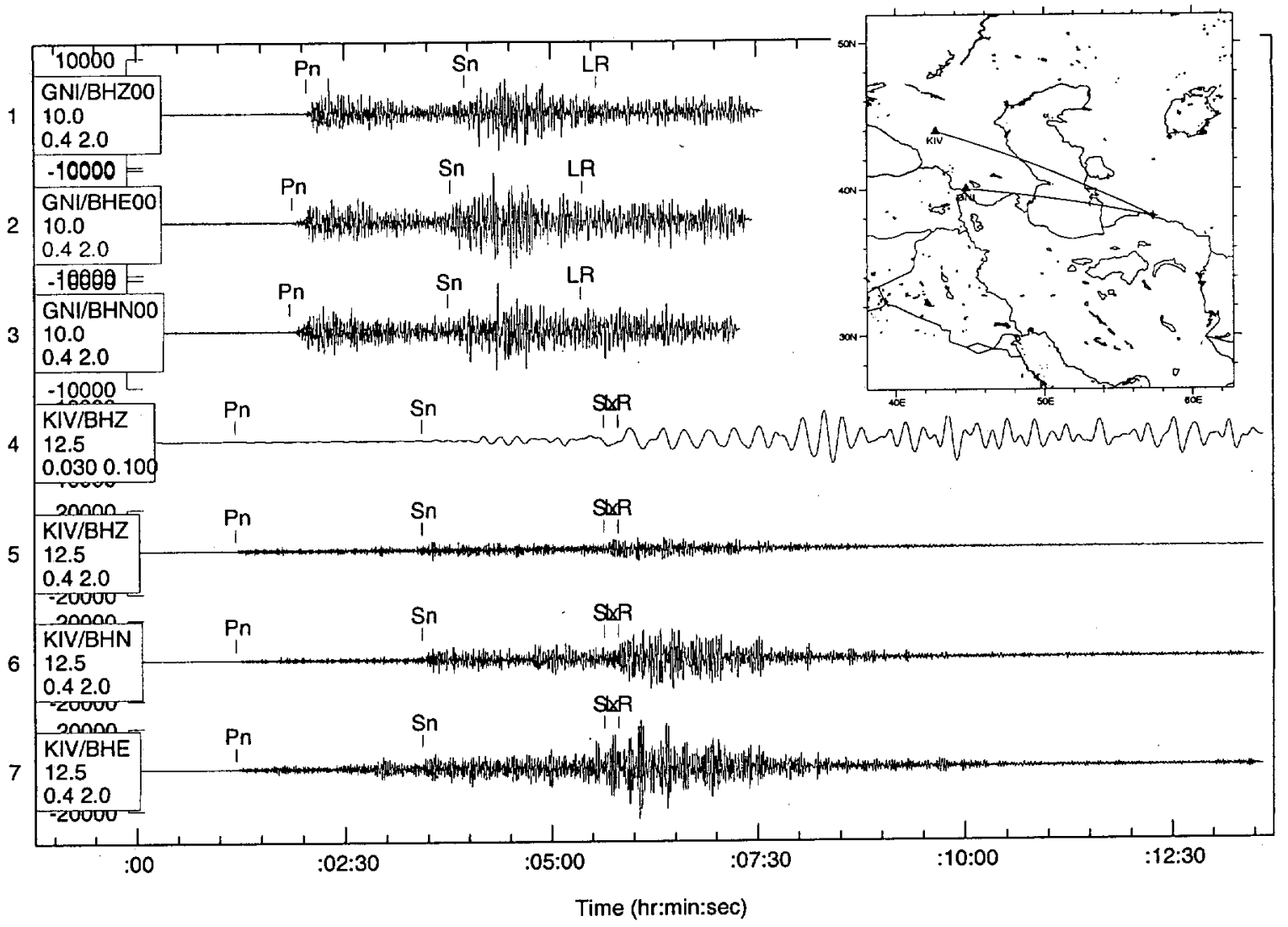

Figure 11. Iran/Turkmenistan Border $h=0 \mathrm{Km}$ mb 5.0.

Figure 11 shows a similar example, of an earthquake in northern Iran recorded at stations KIV and GNI, at distances $10.0^{\circ}$ and $12.5^{\circ}$ respectively. The GNI recording has $\mathrm{Pn}$ and Sn, while KIV records a prominent Sx phase at the predicted time of LR; a long-period recording (middle of the page) shows that LR is also recorded at KIV at about the same time. 


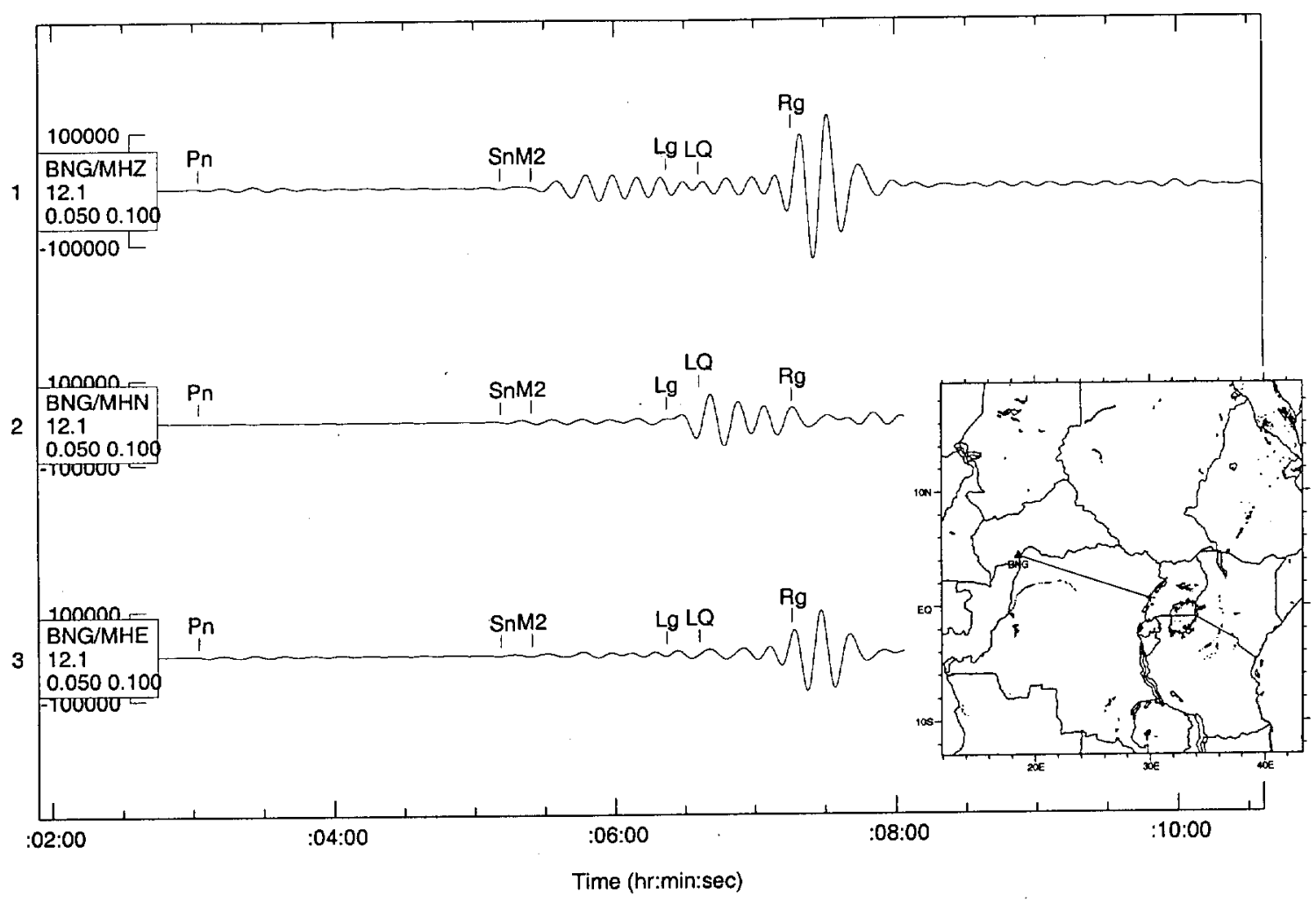

Figure 12. Uganda/Zaire border $\mathrm{h}=14 \mathrm{Km} \mathrm{mb} 5.8$.

Figure 12 shows a Uganda event recorded at the Central African station BNG, distance $12.1^{\circ}$; the recording is band-filtered at $0.05-0.1 \mathrm{~Hz}$. In this case a phase is recorded soon after the $\mathrm{Sn}$ arrival; it has Rayleigh motion, and is labeled as the higher-mode Rayleigh wave M2 after Oliver and Ewing (1957). This phase is also observed over broad areas of the Middle East and for farEastern events recorded in the Middle East. Because it arrives close in time to the S-wave care must be taken by the analyst not to identify it as $S$. 


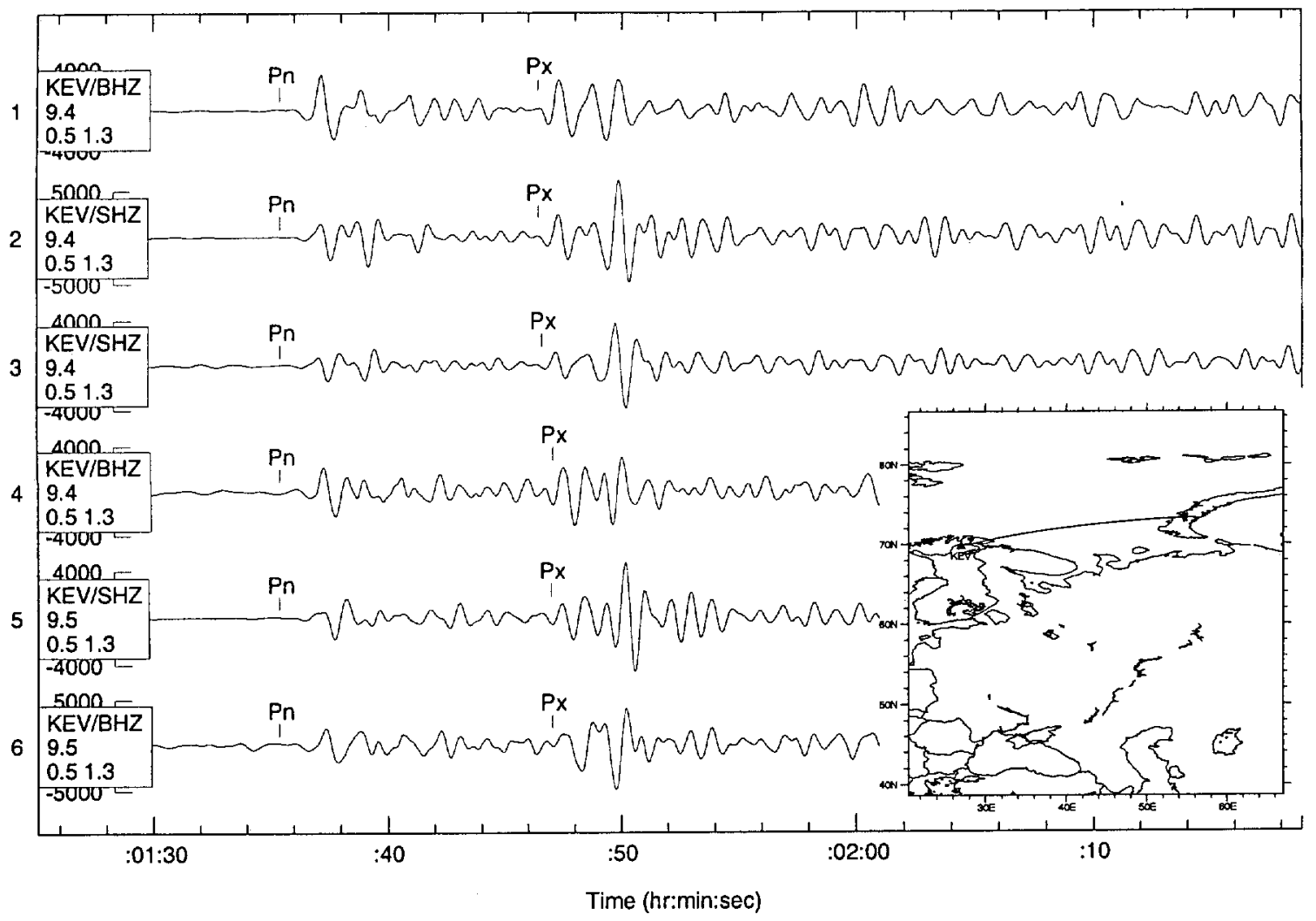

Figure 13. Six NZ Explosions (mb 5.6 to $\mathrm{mb} 5.9$ ).

Figure 13 shows KEV vertical recordings (short-period filter) for six different Novaya Zemlya nuclear explosions, at distances of $9.4^{\circ}-9.5^{\circ}$ (i.e., less than the triplication distance range). All of these have a prominent phase that arrives about 11.5 seconds after the onset of Pn. This phase, labeled Px, is characteristic of the NZ-KEV source-receiver path, at least for explosions. 


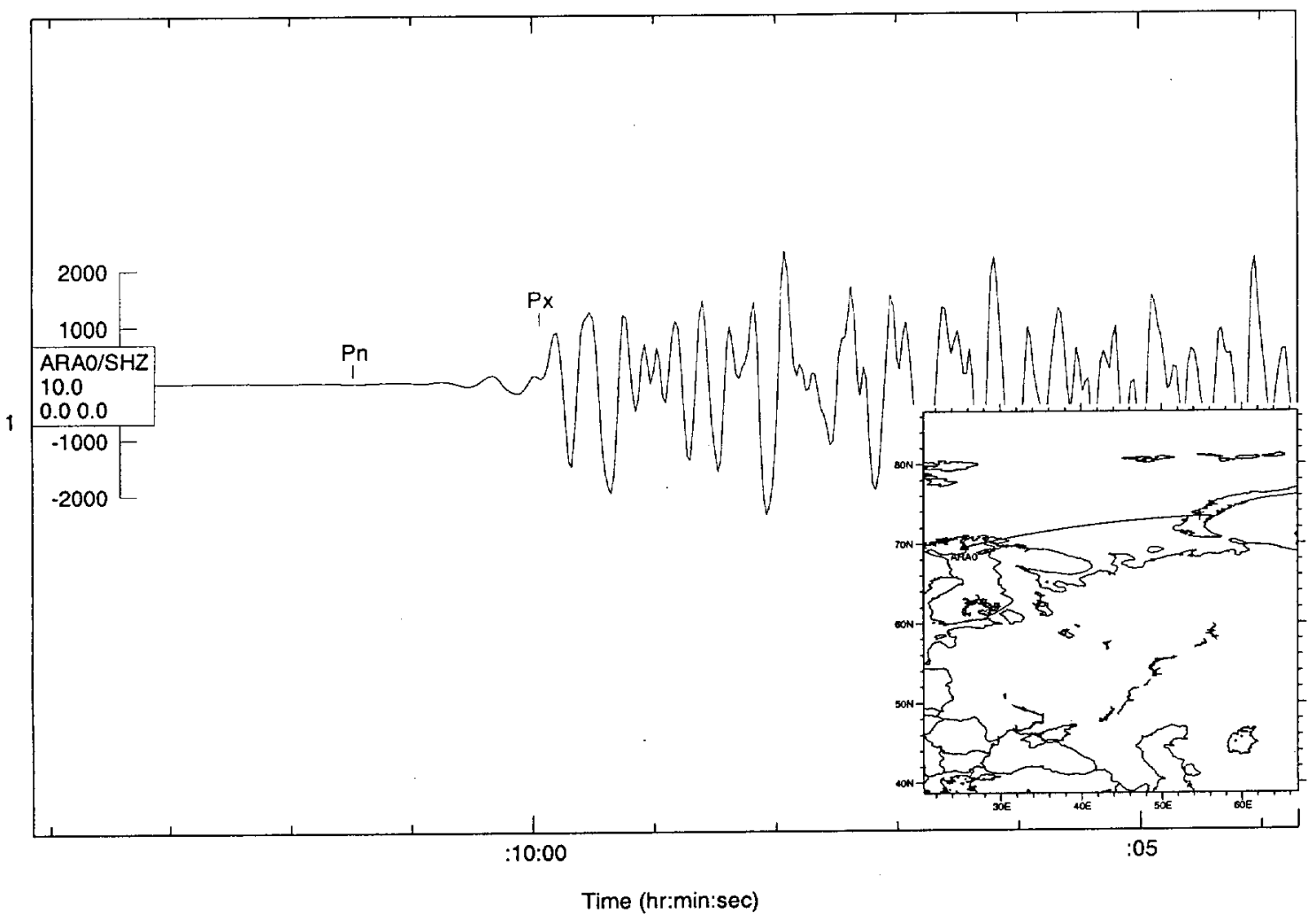

Figure 14. NZ Explosion -- 10/24/90 mb 5.7.

Not shown on Figure 13 is a higher-frequency Px phase that arrives about 1.5 seconds after Pn. Figure 14 shows a similar Px phase for an NZ explosion recorded at ARCESS, distance $10.0^{\circ}$, with Px-Pn time of about 1.5 seconds. It should be noted that the F-K results for the ARCESS recording indicate that the $\mathrm{Pn}$ arrives from the correct backazimuth of $54^{\circ}$, while Px has a backazimuth of $63^{\circ}$; this difference is observed for all three NZ explosions for which we have ARCESS data. 


\section{7) Effects of Magnitude Variation on Arrival Time Picks: Figure 15}

A problem in regional characterization can arise if unfiltered broadband recordings of large events are used to calibrate traveltimes and other parameters, and then these results are applied to the location, magnitude determination and possibly identification of small earthquakes and explosions in the same areas.

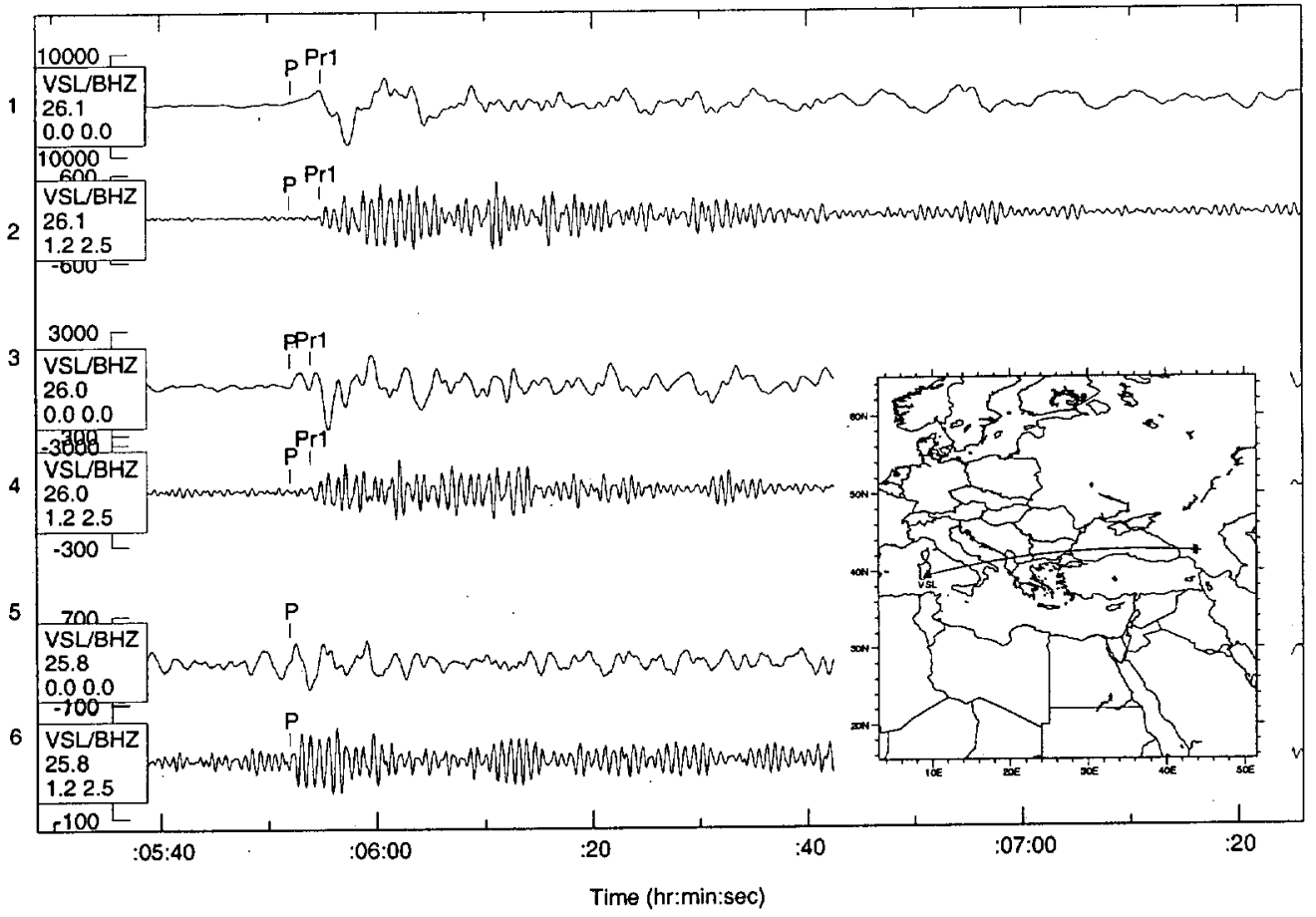

Figure 15. Racha, Georgia Sequence: $\mathrm{mb} 5.9$ (Pr1-P=2.8s); mb $5.5(\operatorname{Pr} 1-\mathrm{P}=1.9 \mathrm{~s})$; mb 4.8.

This phenomenon is illustrated by Figure 15, which shows broadband and short-period-filtered vertical traces at Sardinian station VSL, for earthquakes of the Georgia sequence at teleseismic distances of $25.8^{\circ}-26.1^{\circ}$. The top two traces are for an event with mb 5.9, the next two for an mb 5.5 event and the bottom two for an mb 4.8 event. Note that the filter band $(1.2-2.5 \mathrm{~Hz})$ for the short-period traces was optimized for the detection of a P-onset for the smallest event. On the unfiltered traces the P-wave onset is emergent for the largest event, impulsive for the mb 5.5 shock, and missing for the small event. On the filtered traces, the signal onset ("Pr1") is 2.8 seconds later than the broadband $P$ for the largest event, and 1.9 seconds late for the mb 5.5 event; for the smallest earthquake P could only be picked on the filtered trace. Note also that there is considerable variation in the envelopes of the three short-period signatures, which prevents accurate correlation of the various wave packets from event to event.

In addition, for source-receiver paths where a small phase is followed by a larger one, the small phase can be obscured by noise and missed by the analyst if the event is small. For example, On Figure 14, a small Pn arrival is followed by a large Px for an mb $5.6 \mathrm{NZ}$ nuclear test; for a smallmagnitude event the Pn arrival would be obscured by noise and the analyst would see Px as a first arrival. In this and the previous cases an event could be mislocated due to this effect. 


\section{8) LgRecorded at Teleseismic Distances: Figure 16}

In some regions where long continental paths are available, the phase $\mathrm{Lg}$ can be observed out to teleseismic distances as large as $50^{\circ}$ or more (e.g., for events in Asia recorded in Northern and Central Africa).

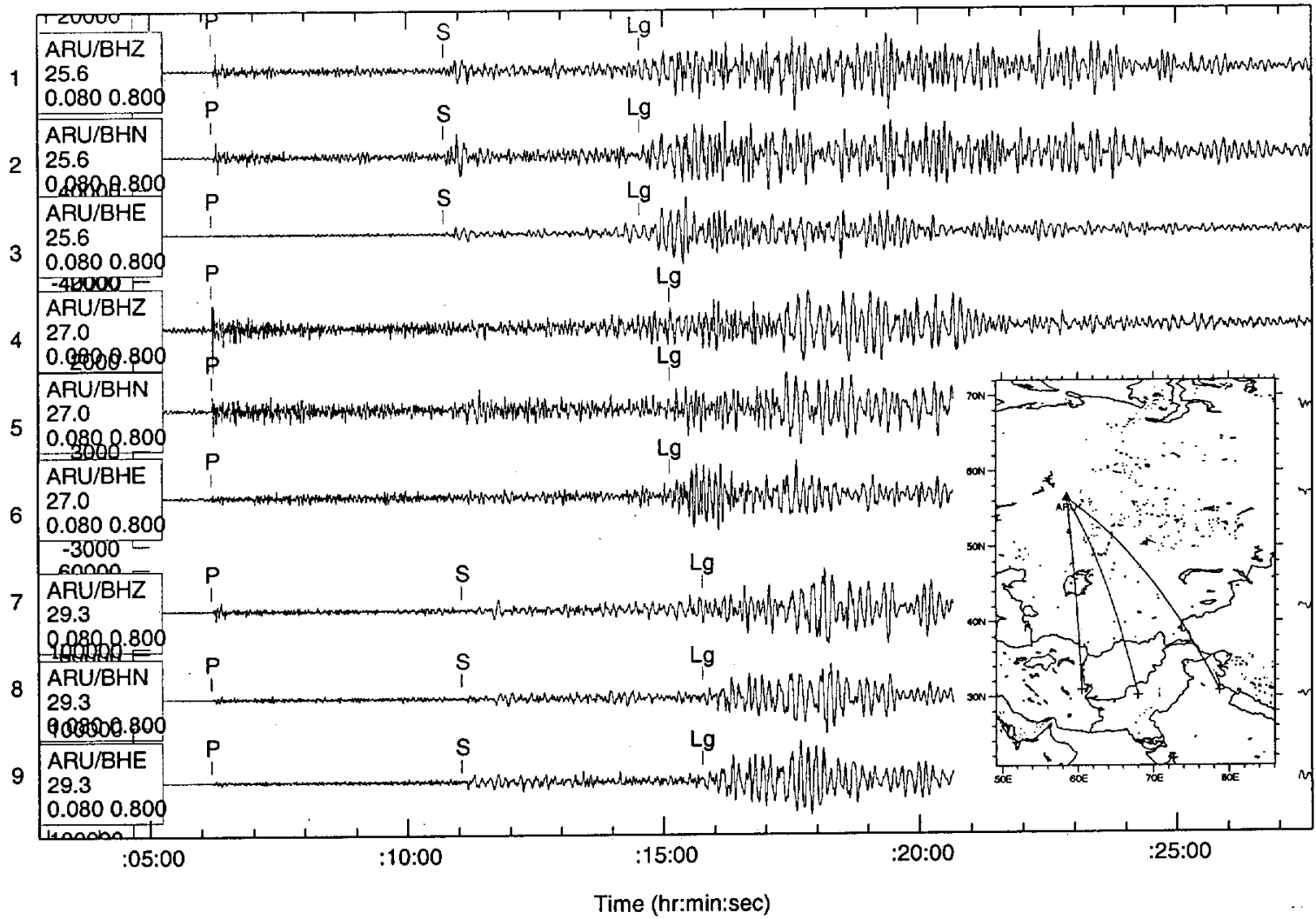

Figure 16. ARU - 3 events, distances $25.6 \mathrm{Km}$ to $29.3 \mathrm{Km}$, note the $\mathrm{Lg}$ recordings. Traces $1-3$ Iran, Traces 4-6 Pakistan, Traces 7-9 Northern India.

Figure 16 shows filtered $(0.08-0.8 \mathrm{~Hz})$ three-component recordings at the Russian station ARU for three events in Afghanistan, Pakistan and India, at distances of $25.6^{\circ}-29.3^{\circ}$. All of these recordings show a prominent $\mathrm{Lg}$ phase. 


\section{9) Possible Complexity at Crossover and Triplication Distances: Figure 17}

As is well-known, seismic signatures can be complex over distance ranges where multiple phases are arriving at about the same time over different paths within the crust and upper mantle. In characterizing a region, it is important to define the range over which these complications occur.

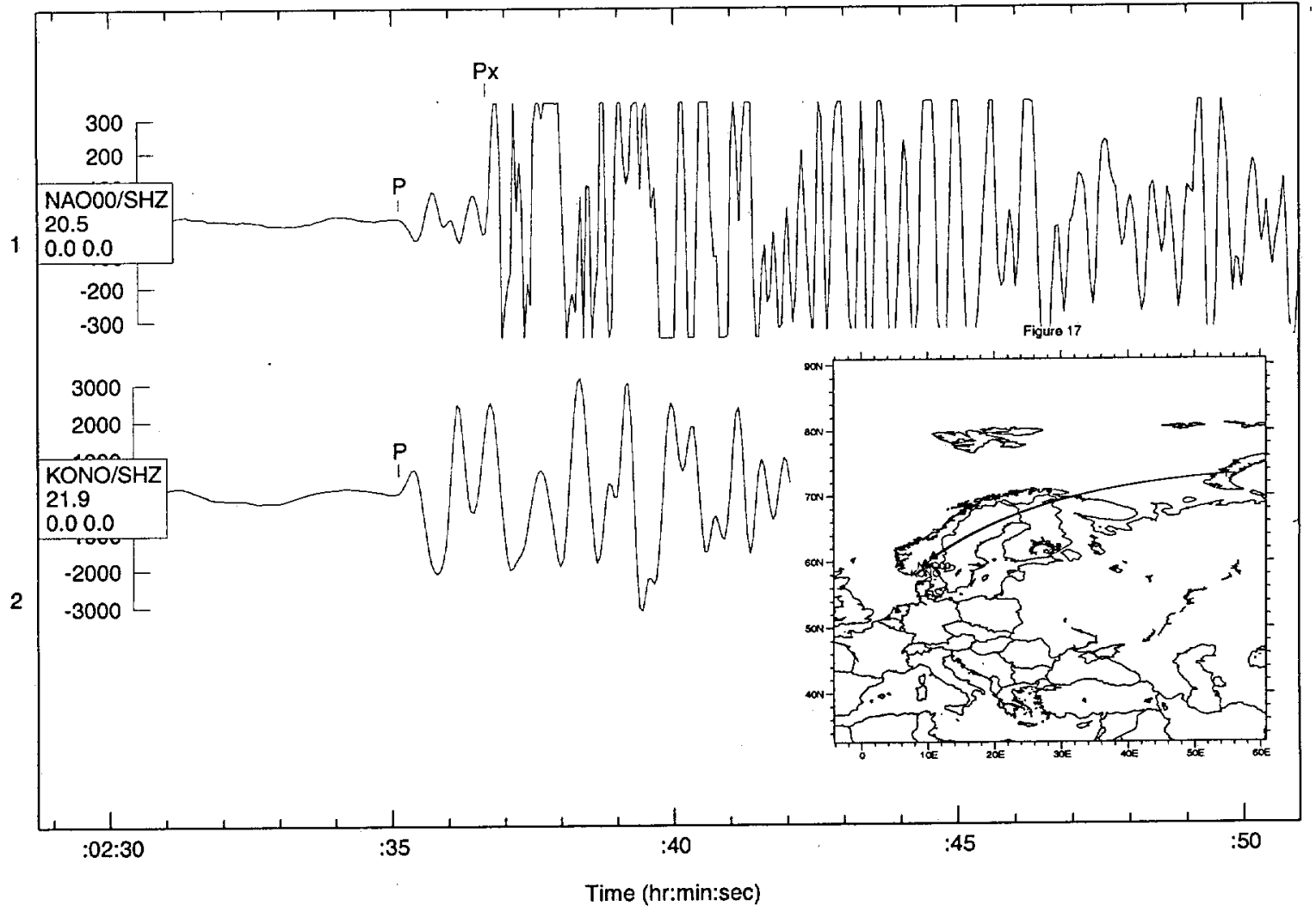

Figure 17. NZ Explosion mb 6.0.

For example, Figure 17 shows recordings of a large NZ explosion at two stations, NORESS and KONO in Scandinavia, at distances of $20.5^{\circ}$ and $21.9^{\circ}$, respectively. At NORESS (top trace) the first onset is a small P-wave, followed after 1.6 seconds by a larger phase, labeled Px; at the more distant station KONO only a single P-wave can be seen. In this region the crossover distance for these two branches of the upper mantle triplication is about $21^{\circ}$. On a previous figure (Figure 4) through the use of filtering, both the regional $\mathrm{Sn}$ and teleseismic $\mathrm{S}$ phases are seen to occur within a few seconds of each other. 


\section{0) S-Wave Scattering.(?) at Far-Regional Distances: Figure 18}

On some paths, a long-duration short-period $S$ phase is observed that arrives at the same time as teleseismic $S$.

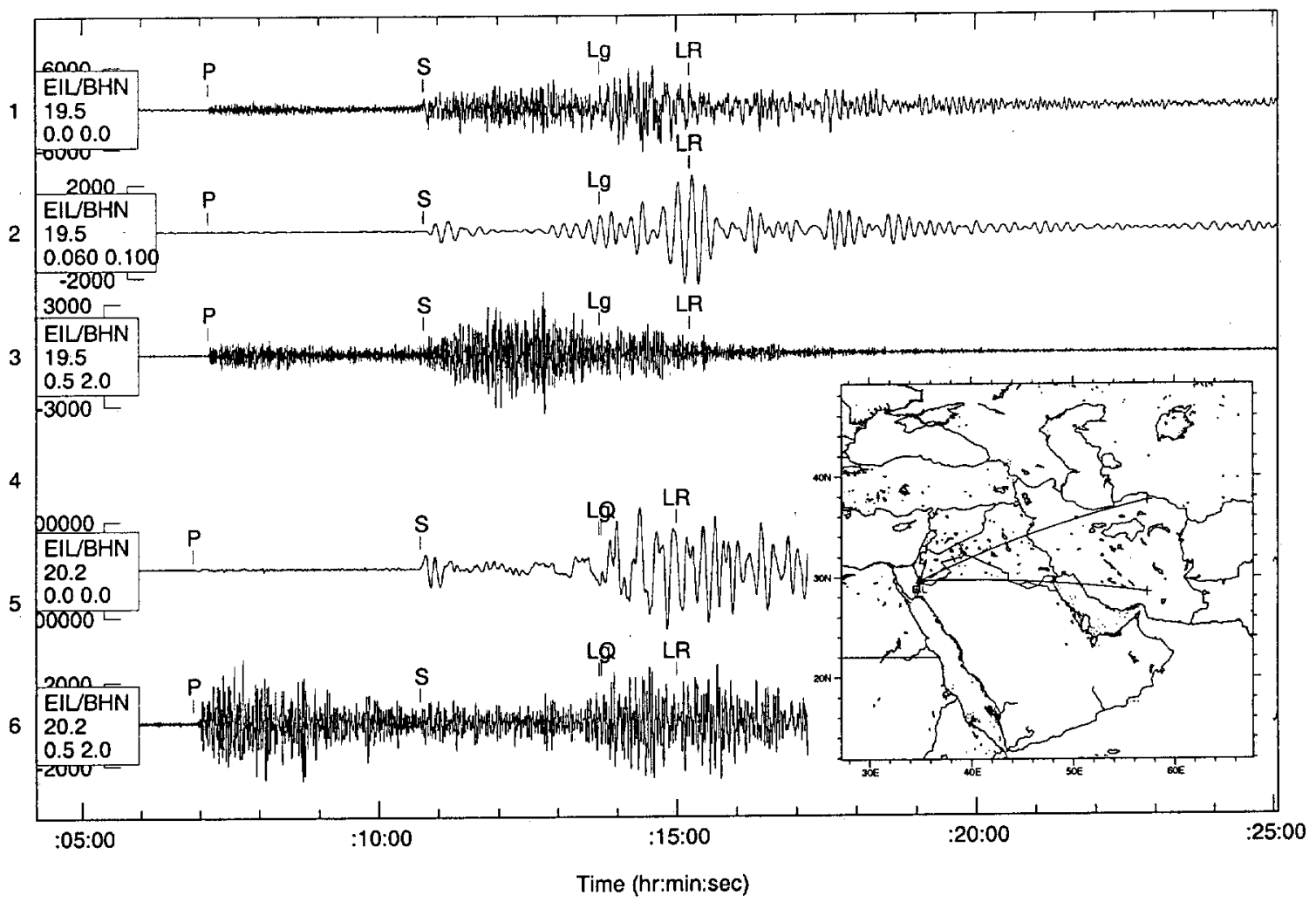

Figure 18. Traces 1-3 Southern Iran, $h=33 \mathrm{Km} \mathrm{mb} 5.6$; Traces 5-6 Northern Iran, $h=10 \mathrm{Km} \mathrm{mb}$ 5.9 .

Figure 18 shows recordings at the Israeli station EIL for two events, respectively, in southern (top traces) and northern (bottom traces) Iran. The southern event produces this phase at EIL, at a distance of $19.5^{\circ}$; the northern event at $20.2^{\circ}$ does not. A similar phase has been observed in other areas - for example, an event in northern Iran records this phase at the Russian station OBN (distance $22.6^{\circ}$ ) while an event in Syria recorded at the same station (distance $20.9^{\circ}$ ) does not. In discussions with LLNL seismologists it was suggested that the short-period signal is possibly due to $S$-wave scattering. This is left as a research problem for the future. 
The problem of mixed events is well known, and is only mentioned here to underscore the need for careful analysis, including filtering and, for array stations, F-K analysis, to resolve ambiguities.

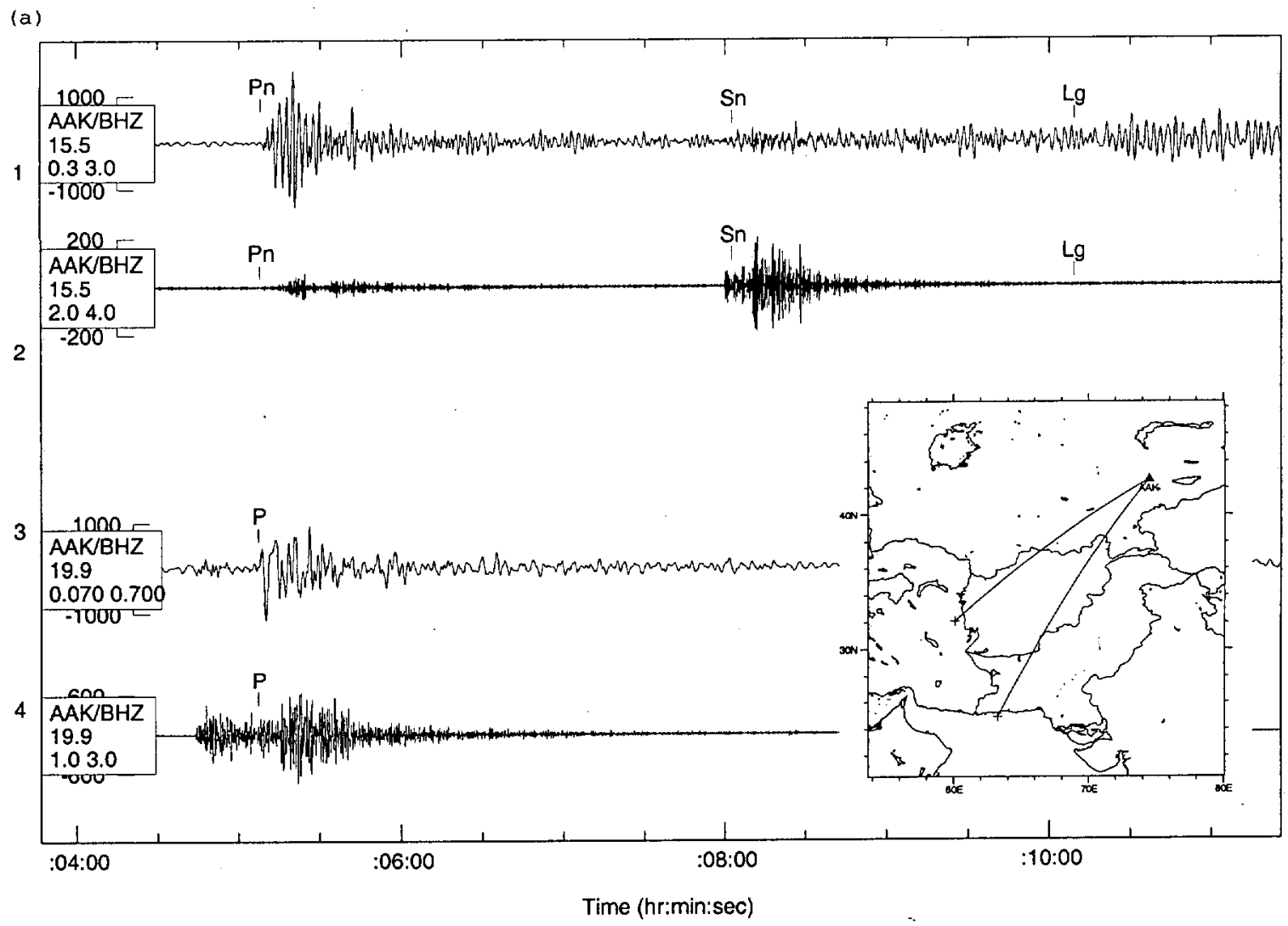




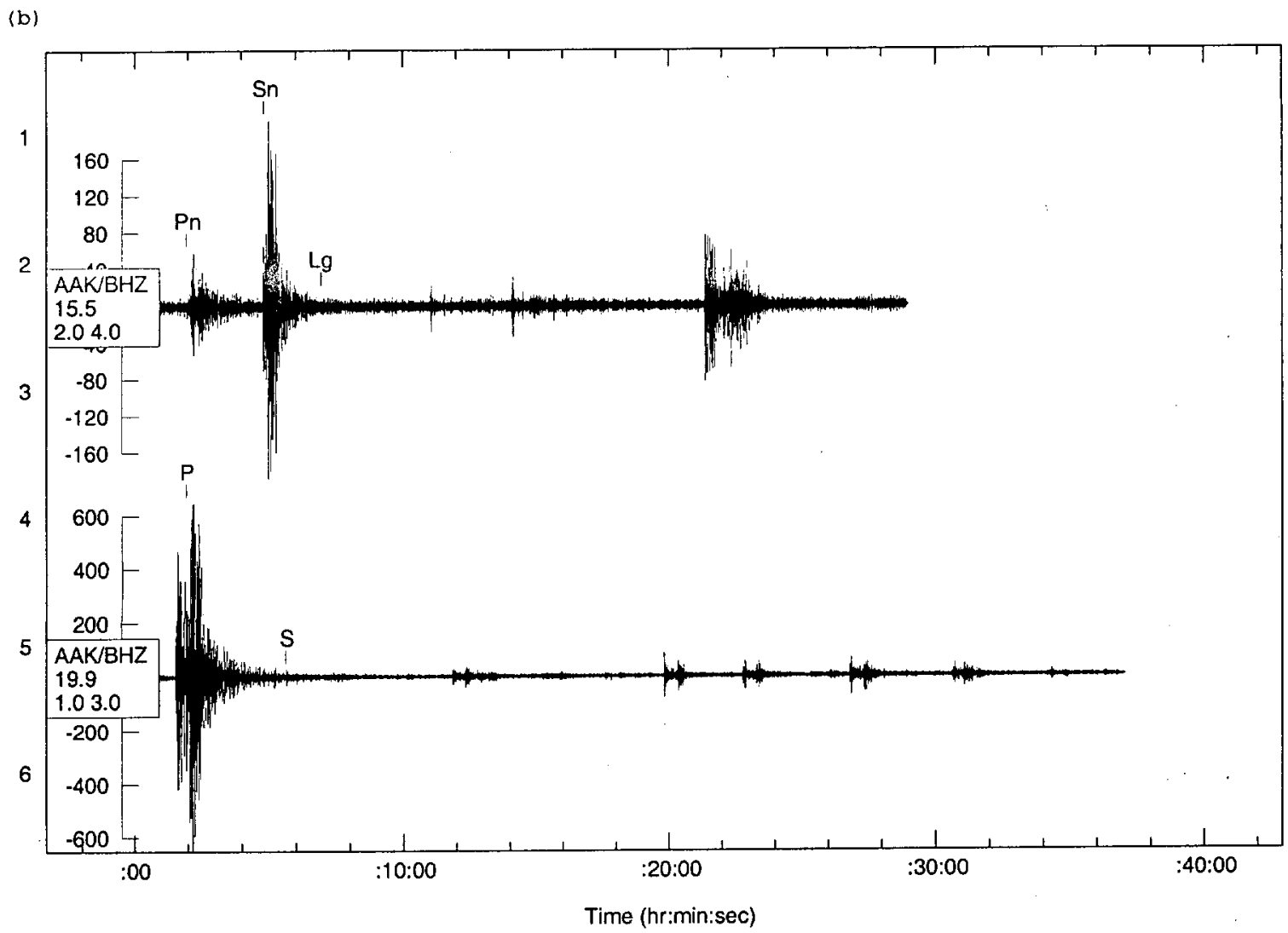

Figure 19. (a) Traces 1-2 E. Iran, $\mathrm{h}=33 \mathrm{Km} \mathrm{mb} 5.1$; Traces 3-4 Off Western Coast of Pakistan,

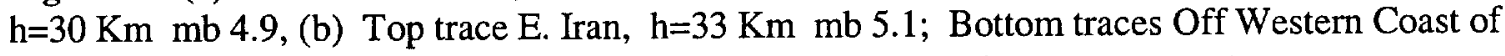
Pakistan, $\mathrm{h}=30 \mathrm{Km} \mathrm{mb} 4.9$.

Figure 19a gives two examples of this. The top trace shows regional phases for an event in eastern Iran recorded at station AAK in the FSU (distance $15.5^{\circ}$ ). These traces have what appears to be a high-frequency $S n$ wave for the regional event; however, on closer inspection (second trace) this high-frequency signal is found to be a separate event of an earthquake swarm near the recording station. The two traces at the bottom of the figure show a similar effect, with the local event arriving with the P-wave of an event off the west coast of Pakistan (distance $19.9^{\circ}$ ). For array stations, F-K analysis can be valuable in separating events arriving from different directions, or phases with different slowness. Figure $19 \mathrm{~b}$ verifies the occurrence of earthquake swarms at the time of both of the events shown in Figure 19a. 


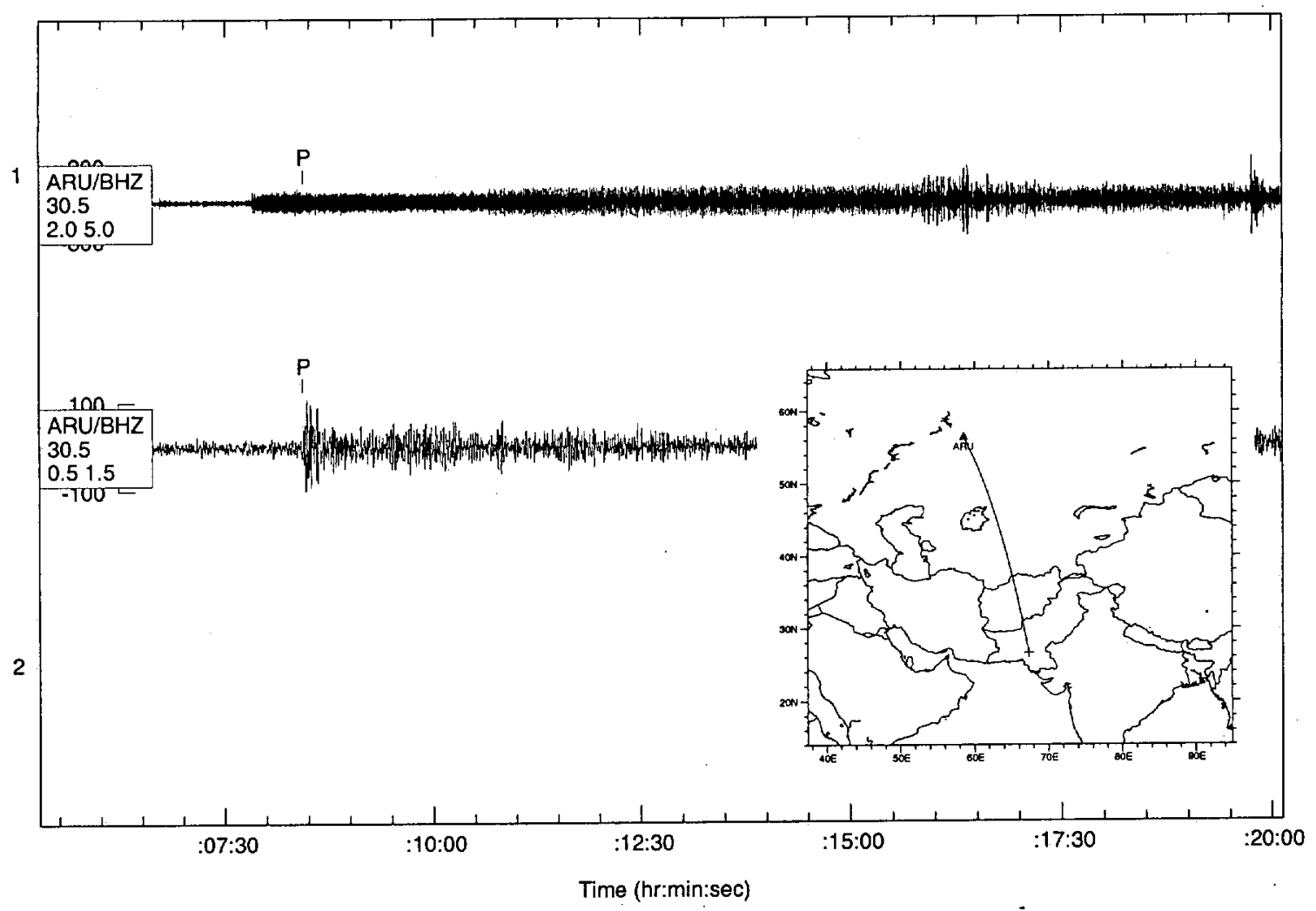

Figure 20. Western Pakistan, $\mathrm{h}=10 \mathrm{Km} \mathrm{mb} 4.9$.

Figure 20 shows another example, of a noise burst in the $2.0-4.0 \mathrm{~Hz}$ band that arrives almost a minute before the P-wave of a Pakistan event recorded at Russian station ARU (distance $30.5^{\circ}$, frequency band $0.5-1.5 \mathrm{~Hz}$ ). 


\section{2) Problems Related to Naming Phases: Figure 21}

In regions of complex tectonic structure, particularly at distances beyond a few hundred kilometers, the analyst (or seismologist) can often be hard-pressed in trying to determine the correct labeling of observed phases. This type of dilemma can arise because of lack of detailed knowledge with regard to crossover distances (e.g., $\mathrm{Pn} / \mathrm{P}, \mathrm{Rg} / \mathrm{LR}$ crossovers) for various crustal and upper-mantle phases, in cases where phases arrive at times significantly different than that predicted by the traveltime curves, or when a particular observation is the result of phase conversion at some structural boundary. In addition, this situation can be further complicated if there are differences of opinion between seismologists about the physical explanation for specific observations.

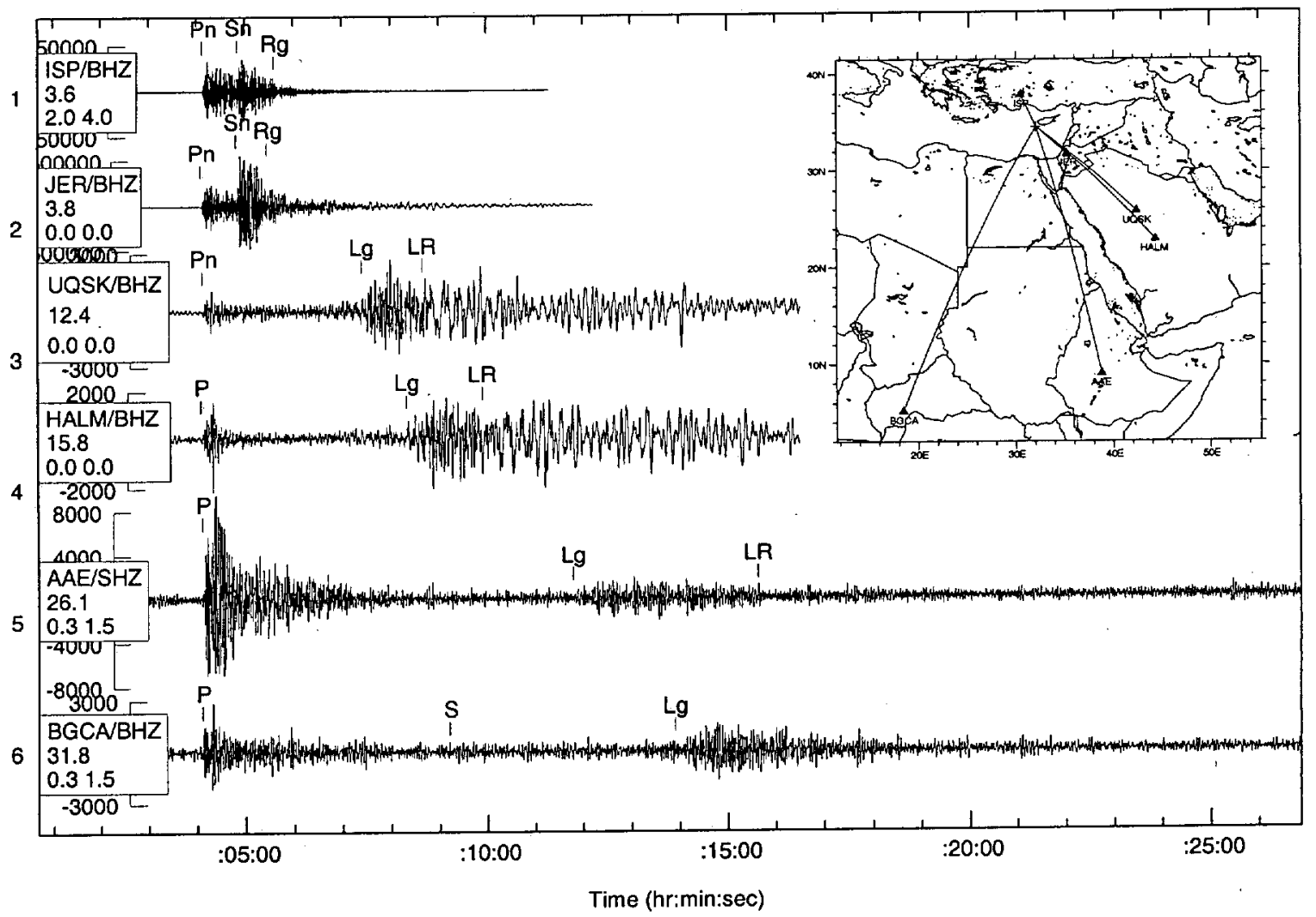

Figure 21. Off Western Coast Cyprus, $h=33 \mathrm{Km} \mathrm{mb} \mathrm{5.0.}$

A case in point is illustrated by Figure 21, which shows recordings at different stations, over a range of azimuths and distances from $3.6^{\circ}$ to $31.7^{\circ}$, for an earthquake off the west coast of Cyprus. At the nearest stations in Israel (JER) and Turkey (ISP) phases Pn, Sn and Rg are observed, but $\mathrm{Lg}$ is not because the source-receiver paths cross the eastern Mediterranean Sea. However, at more distant stations in Africa, an Lg-like phase is recorded that arrives slightly early relative to predicted $\mathrm{Lg}$ times. Initially this phase was labeled $\mathrm{Sx}$, since $\mathrm{Lg}$ was known to be blocked for paths through the eastern Mediterranean. However, after discussions with several seismologists, it was decided that since the phase was probably an $\mathrm{Sn} / \mathrm{Lg}$ conversion at the continental boundary, and most of the path was $\mathrm{Lg}$, the proper phase name should probably be $\mathrm{Lg}$. It should be pointed out that not all cases are this straightforward, and phase naming remains as a major problem in any attempt to "standardize" analysis procedures. 


\section{3) Quality Control and Documentation of Unusual Observations}

In our studies of events in the Middle East, North Africa, Russia and Central Asia, we have encountered examples of stations with clock errors, waveforms with incorrect time windows, noise bursts, and other types of problems that would fall into the category of quality control. These are documented in the "Remarks" tables of the database. In addition, comments are included whenever it is concluded that such comments will help in seismologist review or interpretation of the analyzed data (e.g., description of anomalous phases, mixed events, etc.).

\section{4) Software Issues}

We use the Geotool utility in all analyses because it is menu-driven and includes most of the data processing features needed by the analyst (filtering, alignment of traces, display of predicted arrival times, F-K analysis, event relocation, etc.). There are numerous software issues and possible enhancements that could make this program more efficient and/or easier to use. For example, one particular enhancement that would help greatly in seismologist review of the analysis results, as well as in analyst training, would be a routine that subsequent to analysis would display the seismic trace in the same filter band that the analyst used in picking a particular arrival. To understand the value of such a routine, the reader can imagine a seismologist attempting to review the arrivals displayed on an unfiltered recording like that shown on Figure $3 \mathrm{a}$, as opposed to traces displayed in the filter bands actually used by the analyst to identify and time the various phases (Figure $3 b$ ). The value of a program feature that with one mouse click would display the second of these figures instead of the first is obvious. 


\section{Discussion and Conclusions}

At Livermore we apply rules-by-region. Because the area we are working with is broad and spans a broad set of very complex regions we are forced to define a general set of guidelines and break out rules region-by-region in supplementary reports. For this reason, the analysis procedures described in this document are confined to a flexible set of general guidelines that can handle a broad set of complex regions and smaller magnitude events. We rely on training, ongoing communication between analysts, and careful and continuous documentation to reduce variability between analysts.

In particular, we use filtering extensively - to separate signals from noise, to separate highfrequency from low-frequency phases, to separate events of interest from possible interfering events (e.g., local earthquakes, noise bursts), etc. Without filtering, as illustrated by Figure 3, even moderate-sized events might often be missed entirely at regional distance ranges due to poor signal-to-noise ratio (SNR), or, in the case the event is observable, low amplitude first arrivals may be often missed in the noise.

Furthermore, we use narrow-band filters that are different for different phases, as shown in Figure 3 , and are determined by trial and error for each path of interest. In another example, shown on Figure 4, while a high-frequency Sn phase is clearly displayed by a 3-6 Hz filter, a lowerfrequency teleseismic S-wave buried in the coda of $\mathrm{Sn}$ can be seen on a $0.05-0.5 \mathrm{~Hz}$ band for the same traces. As mentioned in our examples above, identifying both of these phases is important in defining the $\mathrm{Sn} / \mathrm{S}$ crossover distance for particular regions. In most cases, anomalous phases such as Sx in Figure 10 can only be identified with the aid of filters; in regional characterization, these phases may be related to particular structural features along the source-receiver path, and documenting them may therefore be important to event location and/or amplitude analysis. This is important because if anomalous phases are large and of long duration on the recording (e.g., Sx on Figure 10b) they can interfere with phases such as $\mathrm{Lg}$, which is important in both amplitude and magnitude determination (Note: the Lg phase indicated on Figure $10 \mathrm{~b}$ was identified in a different filter band than those shown).

In synthesizing the results of analysis for regional characterization, it will be important to determine, insofar as possible, optimum filter settings for particular phases as a function of source location and source-receiver direction and distance. One approach that we believe will contribute significantly to such a determination is to automatically record filter settings at the time the analysis is done, as recommended above. In addition to providing a way for the seismologist (and/or analyst trainee) to view the recordings in the same way they were seen by the experienced analyst when the phase was identified, the addition of filter settings to the database would permit statistical analyses to be done that might eventually facilitate region-specific automation of the filtering function. At the very least, documentation of filter settings would make it possible to construct "analysis manuals" that would be valid within particular regions. LLNL has begun to include filter settings along with other phase information in the database, but the programs have not yet been written that will permit point-and-click viewing of the filtered waveforms or automated seismic analysis that is optimized for particular regions.

A practice followed at LLNL is for the analyst to make regular presentations to the seismology staff, covering the contents, analysis problems and unique features of a particular dataset. This is useful not only in keeping the researchers aware of available data and potential problems with the data, but it also provides for seismologist feedback to the analyst (e.g., regarding possible explanations for anomalous observations, phase naming conventions, etc.). 
Finally, it should be noted that we have not addressed issues related to depth phases in this report, because such phases are not clearly recorded for the shallow events and regional distance ranges covered in the analysis described here.

\section{Acknowledgments}

We would like to thank Alan Ryall for his thorough review of the document and his insightful input on issues related to the analysis of seismic data. Also we would like to thank Steve Myers and Jerry Sweeney for their aid in generating key figures. Finally, we greatly appreciate the valuable input and feedback from the Livermore staff while preparing the document. This work was performed under the auspices of the U.S. Department of Energy by Lawrence Livermore National Laboratory under contract No. W-7405-ENG-48.

\section{References}

Kandinsky-Cade, K., M. Barazangi, J. Oliver, and B. Isacks (1981). Lateral variations in high frequency seismic wave propagation at regional distances across the Turkish and Iranian Plateaus, J. Geophys. Res., 86, 9377-9396.

Kulhánek, Ota (1990). Anatomy of Seismograms, Elsevier, 178 pp.

Oliver, Jack and Maurice Ewing (1957). Higher modes of continental Rayleigh waves, Bull. Seism. Soc. Am., 47, 187-204.

Sweeney, Jerry (1996). Interpretation of crustal phase characteristics in Iran and the surrounding region determined from ILPA data [abstract], Proc. Seism. Soc. Am. 